\title{
Growth, Public Investment and Corruption with Failing Institution
}

D. de la Croix and Cl. Delavallade

Discussion Paper 2006-57

\section{Département des Sciences Économiques de l'Université catholique de Louvain}




\title{
Growth, Public Investment and Corruption with Failing Institutions
}

\author{
David de la Croix ${ }^{1} \quad$ Clara Delavallade ${ }^{2}$
}

\section{CORE Discussion Paper 2006/101. Revision: May 2008}

\begin{abstract}
Corruption is thought to prevent poor countries from catching up with richer ones. We analyze one channel through which corruption hampers growth: public investment can be distorted in favor of specific types of spending for which rent-seeking is easier and better concealed. To study this distortion, we propose a dynamic model where households vote for the composition of public spending, subject to an incentive constraint reflecting individuals' choice between productive activity and rent-seeking. In equilibrium, the structure of public investment is determined by the predatory technology and the distribution of political power. Among different regimes, the model shows a possible scenario of distortion without corruption in which there is no effective corruption but the possibility of corruption still distorts the allocation of public investment. We test the implications of the model on a set of countries using a two-stage least squares estimation. We find that developing countries with high predatory technology invest more in housing and physical capital in comparison with health and education. The reverse is true for developed countries.
\end{abstract}

Keywords: Public investment, corruption, political power. JEL Classification numbers: O41, H50, D73.

\footnotetext{
${ }^{1}$ Department of Economics and CORE, Université catholique de Louvain.

${ }^{2}$ Centre d'Économie de la Sorbonne, Université Paris 1, CNRS.

Acknowledgements: David de la Croix acknowledges financial support from the Belgian French speaking community (Grant ARC 03/08-235 "New macroeconomic approaches to the development problem") and the Belgian Federal Government (Grant PAI P6/07 "Economic Policy and Finance in the Global Economy: Equilibrium Analysis and Social Evaluation). We are very grateful to Frédéric Docquier, Pierre Pestieau, James Stock and Dirk van de Gaer for helpful suggestions, and to Lennart Hoogerheide for a very detailed and useful internal referee's report. We also thank the participants at the PET06 conference and at seminars in Paris X and World Bank for comments.

E-mail: david.delacroix@uclouvain.be, clara.delavallade@univ-paris1.fr.
} 


\section{Introduction}

Wide-spread corruption seems to be one of the main factors preventing poor countries from catching up with richer ones. Improved institutional efficiency and corruption deterrence are now very high on the agenda of organizations dealing with economic development. The World Bank and the OECD are currently supporting anti-corruption programs to improve governance capacity, promote economic development and fight poverty.

The detrimental effect of corruption on the structure of public expenditure is of particular relevance. Indeed, it has been argued by Mauro (1997), Tanzi (1998) and Delavallade (2006) that education expenditure is scaled down in countries with widespread corruption. Lowering the provision of education has a negative effect on future income, and reinforces economic inequality. The distortion in public spending implied by corruption has been the subject of several empirical studies but has not yet received any attention on the theoretical side. Corruption enhances the proportion not only of military spending (Gupta, Sharan, and de Mello 2000), but also of public services and order, fuel and energy, and cultural expenditure relative to education and health spending (Delavallade 2006). In his influential paper, Mauro (1997) sketches a model based on Barro (1990) with different types of public spending; in his model, corruption acts as a proportional tax on the budget surplus, and does not distort the composition of public spending, contradicting to some extent his empirical results. There is no theoretical paper modelling the possible mechanisms through which corruption may distort the structure of public spending. While the empirical literature on the subject has been confined to estimating the effect of corruption on several types of public spending, and the effect of legal and political institutions on growth (de la Croix and Delavallade 2008), our empirical model sheds new light on the institutional determinants of corruption and their impact on growth through different kinds of budgetary distortions due to corruption.

In this paper, we propose a model which has three distinctive features. First, we define corruption technology as the ease with which rent-seekers can capture part of public spending. Different categories of spending have different corruption technologies, and there are specific types of public spending for which rent seeking is easier and better concealed. Second, individuals vote on the allocation of public investment and rent-seekers may have more political influence than other people. Third, the political economy problem is subject to an incentive constraint, representing the choice made by individuals between productive activity and rent-seeking. The solution to the model 
will display multiple "regimes". In one of them, rent-seekers have considerable political weight, and if the corruption technology is sufficiently efficient, the allocation of public investment will be distorted in favor of specific types of spending (those subject to corruption).

In the empirical part, we analyze how the distinctive features of our model translate into econometric estimates. Using a two-stage least squares estimation based on a set of countries, we examine how the concentration of political power and predatory technology affects the composition of public investment. We find that countries with a high predatory technology invest more in housing and physical capital and less in health and education. A distinctive feature of our approach is to make the marginal effect of corruption technology depend on the level of development. Its effect on the distribution of public spending tends to be weaker in countries with a GDP per capita greater than $\$ 2700$ which is in line with the theoretical viewpoint that there are several different regimes.

The paper is organized as follows. Section 1 presents the structure of the model. The resolution of the voting problem is introduced in Section 2, with a characterization of the different regimes and some numerical illustrations. In Section 3, we report empirical estimate of the main implications of the model, including the description of data, instruments, and tests. Section 4 interprets the results further and provides robustness analyzes of the definition of the public spending variable and the choice of instruments. Section 5 presents our conclusions.

\section{A Dynamic Model of Corruption}

First consider the following assumptions and definitions. Time is discrete and goes from 0 to infinity. At each date, the economy is populated by a mass of identical households $N_{t}$ growing at rate $n$. Households choose between working either in the productive sector or in a rent-seeking activity. We denote by $1-x_{t}$ the share of the population in the productive sector, and by $x_{t}$ the share in the rent-seeking sector.

\subsection{Technology}

There are two types of productive public capital: education and health, $H_{t}$, and physical capital, $K_{t}$. Investment spending in these two types is $G_{t}$ and $I_{t}$. Investment 
in the first type is free from corruption, while investment in the second type is subject to corruption. ${ }^{1}$ Indeed, the first type of investment is composed of predetermined spending like teachers' wages. This involves a more transparent and better controlled spending process than, for example, secret spending, which is included in $I_{t}$. Assessing the impact of $G_{t}$ is easier. Thus, investment spending $G_{t}$ does not leave public officials much room for maneuver and is less subject to arbitrary decisions than investment in the second type of capital $\left(I_{t}\right)$ which concerns more rent-generating capital. And high rents for firms imply high embezzlement for public officials, since those of them who are rent-seekers get a share of the procurement contract or of the profits.

Corruption acts as a tax on investment $I_{t}{ }^{2}$ Rent-seekers are able to extract part of the public investment $I_{t}$ which is proportional to their share in the population. Only a share $1-\nu x_{t}$ of investment spending is effectively invested while $\nu x_{t} I_{t}$ accrues as income for rent-seekers. The parameter $\nu \geq 0$ reflects the corruption technology of the economy. It is positively related to the easiness with which rent-seekers can divert resources. The value $1 / \nu$ should be interpreted as the share of rent-seekers "needed" to divert $100 \%$ of investment. The laws of motion of the two types of capital are:

$$
\begin{aligned}
& H_{t+1}=\left(1-\delta_{H}\right) H_{t}+G_{t} \\
& K_{t+1}=\left(1-\delta_{K}\right) K_{t}+\left(1-\nu x_{t}\right) I_{t}
\end{aligned}
$$

with parameters $\delta_{H}$ and $\delta_{K}$ being the depreciation rates $\left(\delta_{H}, \delta_{K} \in(0,1)\right)$. Denoting the per-capita variables as $h_{t}=H_{t} / N_{t}, g_{t}=G_{t} / N_{t}, k_{t}=K_{t} / N_{t}$ and $i_{t}=I_{t} / N_{t}$, the laws of motion of capital can be rewritten as:

$$
\begin{aligned}
(1+n) h_{t+1} & =\left(1-\delta_{H}\right) h_{t}+g_{t} \\
(1+n) k_{t+1} & =\left(1-\delta_{K}\right) k_{t}+\left(1-\nu x_{t}\right) i_{t} .
\end{aligned}
$$

There is one physical good which is used for consumption and investment in either of the two capital goods. Total production $Q_{t}$ depends positively on labor input $N_{t}\left(1-x_{t}\right)$ and on services from the two types of capital. The production function is written as the product of two terms:

$$
Q_{t}=b\left[N_{t}\left(1-x_{t}\right)\right] f\left[H_{t}, K_{t}\right]
$$

\footnotetext{
${ }^{1}$ This extreme assumption is meant to capture the idea that the degree of exposure to corruption is not identical across categories of public investment.

${ }^{2}$ This is a difference between our model and that developed by Mariani (2006) and Acemoglu (1995) In their model, corruption acts as a tax on producers' income.
} 
The function $b[$.$] is increasing and concave, and satisfies the Inada conditions \lim _{L \rightarrow 0} b^{\prime}[L]$ $=+\infty$ and $\lim _{L \rightarrow+\infty} b^{\prime}[L]=0$. The production function $f[$.$] is increasing and concave.$ As in Arrow and Kurz (1970) and Barro (1990), public capital directly enters the production function. One difference with the previous literature is that here we have two different types of public capital with different exposure to corruption.

We assume that the product $b\left[N_{t}\left(1-x_{t}\right)\right] f\left[H_{t}, K_{t}\right]$ is homogeneous of degree one with respect to labor input $N_{t}\left(1-x_{t}\right)$ and capital inputs $H_{t}$ and $K_{t}$ which allows us to write the output per person $q_{t}=Q_{t} / N_{t}$ as:

$$
q_{t}=b\left[1-x_{t}\right] f\left[h_{t}, k_{t}\right]
$$

This is another difference with Barro (1990). We do not assume constant returns to scale with respect to the factors $h_{t}$ and $k_{t}$, which makes our results comparable to those in the standard neo-classical growth model of Solow (1956) and Arrow and Kurz (1970). Assuming constant return to scale with respect to $h_{t}$ and $k_{t}$ would generate endogenous growth with the usual problems (scale effect of population $N_{t}$ and indeterminacy of the variables in levels) without giving additional insights to those we will find by assuming standard neo-classical growth.

Public investment spending is financed by a lump sum tax $T_{t}$ paid by every citizen:

$$
N_{t} T_{t}=G_{t}+I_{t} \Rightarrow T_{t}=g_{t}+i_{t}
$$

An alternative would have been to tax only the people in the productive sector. This would introduce an additional channel through which corruption plays a role, i.e. by reducing the fiscal basis of the government.

To keep the model as simple as possible we abstract from other types of public spending and from public debt.

\subsection{Household Behavior}

At each date, households consume their income. Income includes either the product of corruption or the return from the productive activity. Their preferences are represented by a utility function $u[$.$] which is assumed to be of the CIES class with inter-temporal$ elasticity of substitution $\sigma$. Since households choose between production and rentseeking, the return from these two activities must be equal at an interior equilibrium. 
The utility of working in the productive sector $U_{t}$ is equal to the utility of the income in this sector. We assume that firms operating in this sector are owned by the workers, or, in other words, that everybody is self-employed. Workers are thus paid the average product

$$
\frac{b\left[N_{t}\left(1-x_{t}\right)\right] f\left[H_{t}, K_{t}\right]}{N_{t}\left(1-x_{t}\right)}=\frac{b\left[1-x_{t}\right]}{1-x_{t}} f\left[h_{t}, k_{t}\right]=\Gamma\left[1-x_{t}\right] f\left[h_{t}, k_{t}\right]
$$

with $\Gamma\left[1-x_{t}\right]=b\left[1-x_{t}\right] /\left(1-x_{t}\right)$. They also pay taxes $T_{t}$. Net income per person is thus

$$
y_{t}=\Gamma\left[1-x_{t}\right] f\left[h_{t}, k_{t}\right]-T_{t}=\Gamma\left[1-x_{t}\right] f\left[h_{t}, k_{t}\right]-g_{t}-i_{t} .
$$

Hence,

$$
U_{t}=u\left[y_{t}\right]
$$

The utility in the rent-seeking sector $V_{t}$ is the utility associated with the income from corruption, net of taxes. Since total income from corruption is $\nu x_{t} i_{t}$, the income per person is $\nu i_{t}$, as long as $x_{t} \leq 1 / \nu$. If $x_{t}=1 / \nu$, all spending $i_{t}$ is diverted by rent-seekers and there is no incentive for the marginal person to move into rent-seeking.

$$
\begin{array}{r}
V_{t}=u\left[\nu i_{t}-g_{t}-i_{t}\right] \text { if } x_{t} \leq 1 / \nu \\
V_{t}=0 \text { otherwise. }
\end{array}
$$

In Figure 1 we represent the payoffs of the two activities. The individual utility from corruption $V_{t}$ does not depend on the share of the population which is corrupt for $x_{t} \leq 1 / \nu$ but decreases to 0 as soon as $x_{t}$ is larger than $1 / \nu$. The utility from the productive sector $U_{t}$ is a positive function of $x_{t}$. Indeed, because of marginal decreasing returns to labor, the function $\Gamma\left[1-x_{t}\right]$ is decreasing in $1-x_{t}$. It decreases from $+\infty$ when $1-x_{t}=0$ to $\Gamma[1]$. Three cases may arise.

In the first case (left panel of Figure 1), the return in the rent-seeking sector is always dominated by that in the productive sector, even when the whole workforce is in the productive sector. In this case, we have

$$
x_{t}^{*}=0
$$

and

$$
\nu i_{t}<\Gamma[1] f\left[h_{t}, k_{t}\right] .
$$

In such a situation, corruption does not exist at all. Condition 4 can be understood as a condition on the parameter $\nu$ relative to the function $b[$.$] . If \nu$ is large enough, i.e. if 

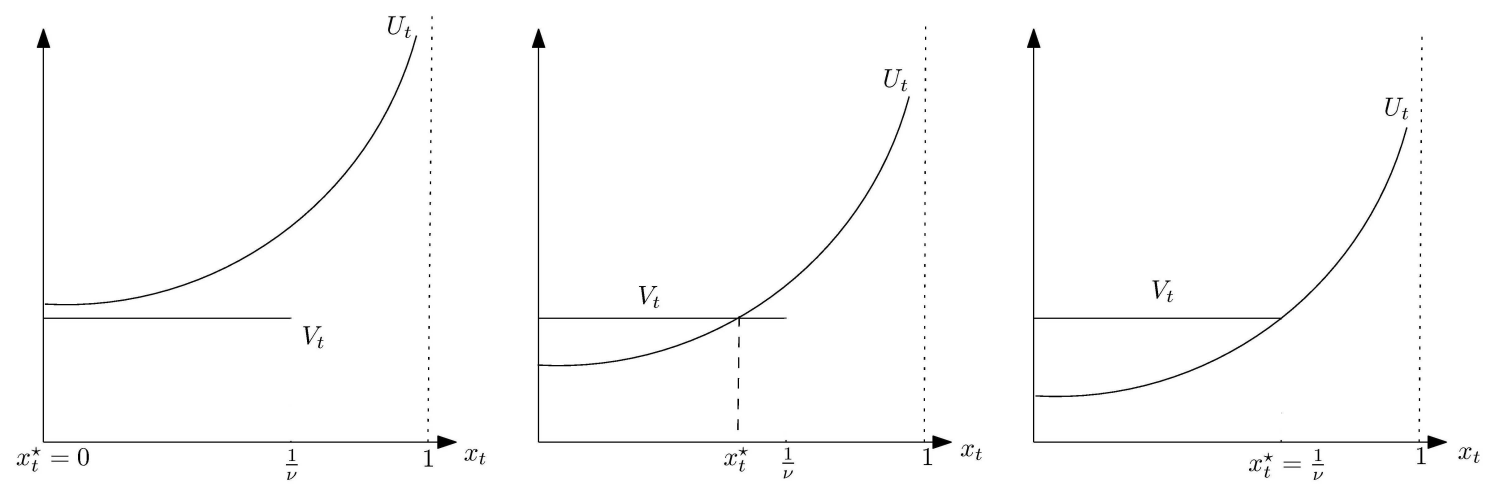

Figure 1: Endogenous corruption: three regimes

the corruption technology is efficient enough, this corner situation will never prevail. In the second case, represented in the central panel of Figure 1, there is a value $x_{t}^{\star} \in$ $(0,1)$ for which households are indifferent between the two activities. Equalizing the two utilities, we obtain the following result.

Proposition 1 If corruption at equilibrium satisfies $x_{t} \in(0,1 / \nu)$, then the following constraint holds:

$$
U_{t}=V_{t} \quad \Rightarrow \quad \Gamma\left[1-x_{t}\right] f\left[h_{t}, k_{t}\right]=\nu i_{t} .
$$

Condition (5) states that, at equilibrium, there is a relation between the share of the population in the rent-seeking sector and public capital $\left(h_{t}\right.$ and $\left.k_{t}\right)$, the effectiveness of corruption technology $(\nu)$, and the amount of public spending subject to corruption $\left(i_{t}\right)$. This relation, which describes the choice of activity by households, will act as a constraint for the political economy problem. We label it the incentive constraint.

Condition (5) makes the level of corruption endogenous at equilibrium. It is similar to that found in the models of corruption presented by, inter alia, Shleifer and Vishny (1993), Banerjee (1997), and Acemoglu and Verdier (2000). Compared to this literature, our set-up makes two breakthroughs. First, we model corruption explicitly by modeling which resources are captured by rent-seekers and by distinguishing between the two types of government spending. Second, our model is a dynamic model, bridging the gap between the standard theory of growth and the mostly static theory of corruption. 
In the third case (right panel of Figure 1), the income possibilities from rent-seeking are exhausted: $x_{t}^{*}=1 / \nu$. In this case we have

$$
\nu i_{t}=\Gamma[1-1 / \nu] f\left[h_{t}, k_{t}\right]
$$

In this case, investment $i$ is entirely diverted, implying that the stock of capital $k$ shrinks. Finally, there is a fourth possibility with $\nu i_{t}>\Gamma[1-1 / \nu] f\left[h_{t}, k_{t}\right]$; this would represent a situation where rent-seeking was more profitable than productive activity, but the corruption possibilities were completely exhausted, so that those who worked in the productive sector had a lower income which was still better than the zero income they would have got if they had chosen rent-seeking for themselves.

If the situation described in the latter two cases persists, income in the productive sector tends to zero, which cannot be an optimal solution. Hence these regimes can only appear temporarily. In the following sections we will assume that $x_{t}<1 / \nu$ at equilibrium, i.e. we will rule out the possibility of maximum corruption because it is unrealistic and cannot be a long-run equilibrium.

\subsection{Voting on Public Investment}

The levels of public investment $g_{t}$ and $i_{t}$, and hence taxes $T_{t}$, are chosen through probabilistic voting. Assume that there are two political parties, $a$ and $b$. Each one proposes a policy. Instead of assuming that an individual votes for party $a$ with probability one every time party $a$ 's policy gives him/her higher utility (as in the median voter model), probabilistic voting theory supposes that this vote is uncertain. More precisely, the probability that a person votes for a given party $a$ is a smooth function of the utility gain associated with the implementation of policy $a$. This function captures the idea that voters care about an "ideology" variable in addition to the specific policy measure at hand. The presence of a concern for ideology, which is independent of the policy measure, makes the political choice less predictable (see Persson and Tabellini (2000) for various formalizations of this approach). The probability that a given voter will vote for party $a$ increases gradually as the party's platform becomes more attractive. Party $a$ maximizes its expected vote share. Party $b$ acts symmetrically, and, at equilibrium, the two proposed policies coincide. The maximization program of each party 
implements the maximum of the following weighted social welfare function: ${ }^{3}$

$$
\max \sum_{t=0}^{\infty} \rho^{t} W_{t} \text { subject to }(1),(2),(8) \text {, and given } H_{0}, K_{0} \text {. }
$$

with

$$
W_{t}=\left(1-x_{t}\right) U_{t}+(1+\theta) x_{t} V_{t}
$$

and

$$
\nu i_{t} \leq \Gamma\left[1-x_{t}\right] f\left[h_{t}, k_{t}\right]
$$

The parameter $\theta$ is the additional weight attached to the people in the rent-seeking sector. From probabilistic theory, it captures the responsiveness of voters to the change in utility. In particular, a group that has little ideological bias cares relatively more about economic policy. Such groups are therefore targeted by politicians and enjoy high political power. ${ }^{4}$ If $\theta=0$ the problem can be interpreted as that of a benevolent social planner giving equal weight to all citizens; if $\theta=\infty$, the social planner is the kleptocratic government envisioned by Kanczuk (1998), maximizing the discounted flow of income from corruption. Notice that this maximization problem can alternatively be interpreted in the light of the lobbying literature (see Bernheim and Whinston (1986)).

\section{Solution Characteristics}

To solve the planning problem we write the following infinite Lagrangian:

$$
\begin{aligned}
& \sum_{t=0}^{\infty} \rho^{t}\left\{W_{t}+\rho \lambda_{t+1}\left[\left(1-\delta_{H}\right) h_{t}+g_{t}-(1+n) h_{t+1}\right]\right. \\
& +\rho \mu_{t+1}\left[\left(1-\delta_{K}\right) k_{t}+\left(1-\nu x_{t}\right) i_{t}-(1+n) k_{t+1}\right] \\
& \left.+\phi_{t}\left[\Gamma\left[1-x_{t}\right] f\left[h_{t}, k_{t}\right]-\nu i_{t}\right]+\omega_{t} x_{t}\right\} .
\end{aligned}
$$

The variables $\lambda_{t}$ and $\mu_{t}$ are the Lagrange multipliers associated with the equality constraints (1) and (2). The variables $\phi_{t}$ and $\omega_{t}$ are the Kuhn-Tucker multipliers

\footnotetext{
${ }^{3}$ This result was first derived by Coughlin and Nitzan (1981).

${ }^{4}$ An alternative view is that households can gain political power by purchasing votes (see, for example, Docquier and Tarbalouti (2001)).
} 
associated with the constraints:

$$
\begin{aligned}
\nu i_{t} & \leq \Gamma\left[1-x_{t}\right] f\left[h_{t}, k_{t}\right] \\
0 & \leq x_{t}
\end{aligned}
$$

The multiplier $\phi_{t}$ associated with the incentive constraint is the shadow price of corruption, reflecting the idea that the choice of the allocation of public spending has an effect on the type of activity chosen by households. For example, if the government increases the amount of spending subject to corruption more households will work in the rent-seeking sector ( $\phi_{t}$ is higher).

At each date, four possible cases are a priori possible, depending on which constraint is binding. Among these, only three are logically possible. Let us consider these cases in turn, which we label by the sign of the vector $\left(\phi_{t}, \omega_{t}\right)$.

1. $(0,0)$ This case is not possible because $\omega_{t}=0 \rightarrow x_{t}>0$ which implies that the incentive constraint should be binding, and thus $\phi_{t}>0$.

2. $(+, 0)$ This is the interior regime with $0<x_{t}$ (central panel of Figure 1$)$.

3. $(0,+)$ This is the regime where Equation (4) holds, so that the incentive constraint is not binding. There is no corruption and public investment is not distorted (left panel of Figure 1). We label this case the benchmark regime.

4. $(+,+)$ This case corresponds to a situation without corruption, where Equation (4) does not hold. The incentive constraint holds with equality at $x_{t}=0$ reflecting the fact that the government has to lower investment $i_{t}$ in order to deter households from rent-seeking (left panel of Figure 1). We label this case distortion without corruption.

Note that these cases stand for three regimes at a unique equilibrium, and not for three different equilibria. They correspond to different values of the parameters at the same equilibrium. Multiple equilibria usually arise in decentralized economies when the level of corrupt activity influences its return (Bardhan 2006), as for example if, when many others are rent-seekers, it was in one's interest to be a rent-seeker as well.

The optimality conditions are derived in Appendix A for the three possible regimes. From these conditions we can derive one relation between the marginal productivity of the two types of capital. Let us consider the different regimes in turn. 


\section{$2.1 \quad$ Benchmark Regime}

The case without corruption can be seen as a benchmark against which we can evaluate the cases with corruption. From the first-order conditions analyzed in Appendix A we derive:

$$
\lambda_{t}=\mu_{t}, \quad \forall t .
$$

Here, there is no distortion, and the shadow price of both types of capital should be equal at all times. From Appendix A we also find that:

$$
1-\delta_{H}+\Gamma[1] f_{H}^{\prime}\left[h_{t}, k_{t}\right]=1-\delta_{K}+\Gamma[1] f_{K}^{\prime}\left[h_{t}, k_{t}\right] .
$$

At equilibrium the marginal productivity of the two types of capital should be equal. This condition is comparable to that in Arrow and Kurz (1970). They propose an optimal growth model with two types of capital, one of which contributes directly to the utility of households. The optimal condition from the political problem states that the marginal productivity of the first type of capital should equal the marginal productivity of the second type plus its marginal effect on utility. This last term is not present in our set-up since capital does not affect utility directly.

The benchmark case arises if Condition (4), which can be interpreted as an upper bound on the corruption technology $\nu$, holds. Moreover, there is another condition for this regime to prevail. It is derived in Appendix A from the positivity of the Kuhn-Tucker multiplier $\omega_{t}$ associated with $x_{t} \geq 0$. This condition is written:

$$
1+\theta<\frac{u\left[y_{t}\right]+u^{\prime}\left[y_{t}\right]\left(\nu i_{t}+\Gamma^{\prime}[1] f\left[h_{t}, k_{t}\right]\right)}{u\left[\nu i_{t}-g_{t}-i_{t}\right]} .
$$

It requires $\theta$ not to be too large. For a given corruption technology $\nu$, if $\theta$ is large, rent-seekers have much more political weight than productive workers, and it is less likely that the equilibrium without corruption could prevail. The precise conditions on the parameters under which the interior regime arises can be established for long-run equilibria. In the long-run, all the variables $H_{t}, K_{t}, G_{t}, I_{t}$ and $Y_{t}$ grow at the same rate $n$. All the per capita variables converge to a constant level. The following proposition establishes the two essential properties of the equilibrium without corruption and the conditions to reach it. 
Proposition 2 In a long-run equilibrium, if

$$
\nu<\frac{\Gamma[1] f[h, k]}{\left(n+\delta_{K}\right) k}
$$

and

$$
1+\theta<\frac{u[y]+u^{\prime}[y]\left(\nu\left(n+\delta_{K}\right) k+\Gamma^{\prime}[1] f[h, k]\right)}{u\left[(\nu-1)\left(n+\delta_{K}\right) k-\left(n+\delta_{H}\right) h\right]} .
$$

with $h$ and $k$ given by (14) and (15), then.

1. There is no corruption: $x=0$.

2. The marginal productivity of both types of capital is equal:

$$
1-\delta_{H}+\Gamma[1] f_{H}^{\prime}[h, k]=1-\delta_{K}+\Gamma[1] f_{K}^{\prime}[h, k] .
$$

3. The Modified Golden Rule holds:

$$
1-\delta_{H}+\Gamma[1] f_{H}^{\prime}[h, k]=\frac{1+n}{\rho} .
$$

Proof: See Appendix A.

Equation (15) is a Modified Golden Rule. The marginal productivity of capital is equal to the growth in population divided by the discount factor $\rho$. Equation (14) determines the optimal mix of investment at steady state. Conditions (12) and (13) show that such a regime with no distortion will prevail if the corruption technology is not too efficient, and if the political weight of rent-seekers is not too high. In the next section, we present, through a numerical example, the zone in the space $\{\nu, \theta\}$ for which this regime holds.

\subsection{Distortion without Corruption}

In this regime, the incentive constraint holds with equality at $x_{t}=0$ reflecting the fact that the government has to lower investment $i_{t}$ in order to deter households from rent-seeking. This is reflected by the following relation from Appendix A:

$$
\lambda_{t+1}=\mu_{t+1}-\frac{\phi_{t} \nu}{\rho}
$$


Comparing this with Equation (9) shows that the shadow prices of capital are no longer equal. The value of $h(\lambda)$ is reduced compared to the value of $k(\mu)$, indicating that there is less capital $k$ in the economy as a consequence of the drop in investment $i$ necessary to deter corruption. The term $\phi_{t} \nu / \rho$ represents the distortion brought about by the possibility of corruption. In this regime, corruption acts like a negative externality which can be limited at a certain cost.

At steady state, we obtain a modified "Modified Golden Rule" that incorporates corruption:

$$
1-\delta_{H}+\Gamma[1-x] f_{H}^{\prime}[h, k]=\frac{1+n}{\rho}-\phi \frac{\Gamma[1] f_{H}^{\prime}[h, k]}{u^{\prime}[y]}
$$

The net marginal productivity of capital is equal to the discounted growth rate of population minus a term depending on the shadow price of corruption. As $\phi>0$, the incentive constraint has a positive impact on investment in $h$, given the stock $k$, and makes the productive sector more rewarding which allows corruption to be kept out of the economy.

To assess the effect of the possibility of corruption on the composition of public investment, consider the ratio $g / i$ at steady state:

$$
\frac{g}{i}=\frac{n+\delta_{H}}{n+\delta_{K}} \frac{h}{k}
$$

Compared to the benchmark case, we have seen above that $h / k$ is higher when the incentive constraint is binding. As a consequence the ratio $g / i$ will be higher too. In this regime, the possibility of corruption increases the share of public spending free from corruption. This shows that the possibility of corruption does not always distort public investment in favor of specific types of spending for which rent-seeking is easier and better concealed as suggested in the empirical literature.

\subsection{Interior Regime}

In this case, Constraint (4) holds. The relation linking the shadow prices of capital becomes:

$$
\left(1-\frac{\nu x_{t}(1+\theta)}{1+\theta x_{t}}\right) \lambda_{t+1}=\mu_{t+1}\left(1-\nu x_{t}\right)-\frac{\phi_{t} \nu}{\rho} .
$$

To better understand this relation compared to (9) and (16), it is useful to compute its value when rent-seekers do not enjoy additional political power, i.e. $\theta=0$. Then 
we have:

$$
\lambda_{t+1}=\mu_{t+1}-\frac{\phi_{t} \nu}{\rho\left(1-\nu x_{t}\right)} .
$$

This relation is quite similar to (16). We have the same mechanism: the choice of capital is distorted in favor of that which is not subject to corruption in order to deter households from working in the rent-seeking sector. When $\theta>0$, however, there is a force which will work in the opposite direction: since rent-seekers have more weight than workers, the government has a tendency to increase the spending subject to corruption in order to "feed" the rent-seekers. This tendency is reflected by the term on the left-hand-side, ${ }^{5}$

$$
1-\frac{\nu x_{t}(1+\theta)}{1+\theta x_{t}}
$$

Hence two forces work in opposite directions: the interest of having households working in the productive sector against the additional utility drawn from the presence of rentseekers.

To better understand the role of the incentive constraint, we look at the optimal value of the corresponding multiplier, $\phi_{t}$, the shadow price of corruption. From the optimality conditions of Appendix A, we obtain:

$$
\phi_{t}=\frac{-\theta u\left[y_{t}\right]+\nu \rho \mu_{t+1} i_{t}-\left(1-x_{t}\right) u^{\prime}\left[y_{t}\right]\left|\Gamma^{\prime}\left[1-x_{t}\right]\right| f\left[h_{t}, k_{t}\right]}{\left|\Gamma^{\prime}\left[1-x_{t}\right]\right| f\left[h_{t}, k_{t}\right]}>0 .
$$

The shadow price of corruption is the sum of three terms. The first term $-\theta u\left[y_{t}\right]$ is the direct effect of $x_{t}$ on the objective function $W_{t}$. For a correct interpretation of this term, we need to assume that the utility function is positive which requires $\sigma>1$ with the CIES functional form. When corrupt individuals carry more political weight $(\theta>0)$, the cost of the constraint is decreased. The second term $\nu \rho \mu_{t+1} i_{t}$ is positive and reflects the loss of investment and future capital because of corruption. This second term weighs more if the corruption technology $(\nu)$ is more efficient. The third term is negative: if there is more corruption, fewer people work in the productive sector, but their individual productivity is higher because of decreased marginal returns to labor.

At steady state, the modified "Modified Golden Rule" is:

$$
1-\delta_{H}+\Gamma[1-x] f_{H}^{\prime}[h, k]=\frac{1+n}{\rho}-\phi \frac{\Gamma[1-x] f_{H}^{\prime}[h, k]}{(1-x) u^{\prime}[y]} .
$$

\footnotetext{
${ }^{5}$ This term decreases from $1-\nu x_{t}$ to $1-\nu$ as $\theta$ goes from 0 to $+\infty$. It therefore increases $\lambda$ compared to $\mu$ as $\theta$ rises (ceteris paribus) which goes against the effect of the incentive constraint, $\phi_{t} \nu / \rho\left(1-\nu x_{t}\right)$.
} 
As in the previous case, the incentive constraint has a positive impact on investment in $h$, given the stock $k$. To assess the effect of corruption on the composition of public investment, consider the ratio $g / i$ at steady state:

$$
\frac{g}{i}=(1-\nu x) \frac{n+\delta_{H}}{n+\delta_{K}} \frac{h}{k}
$$

Compared to the previous regime, there is now a term $(1-\nu x)$ involved in the relation between the two ratios. This term shows that some investment is diverted from its purpose, highlighting how corruption acts as a tax. Even if $h / k$ is increased compared to the benchmark, $g / i$ may well be decreased if corruption $\nu x$ is strong enough.

\subsection{Numerical Illustration}

To illustrate the properties of the model, we ran a numerical example. We first gave the following specific forms to our functions:

$$
b[1-x]=(1-x)^{\alpha}, \quad f[k, h]=k^{\beta} h^{\epsilon} .
$$

We assume population growth at rate $n=0.005$, a discount factor of 0.96 , and depreciation rates of $\delta_{H}=\delta_{K}=0.04$. The technology parameters are set at $\alpha=1 / 2, \beta=1 / 4$ and $\epsilon=1 / 4$. The intertemporal elasticity of substitution is set at $\sigma=2$. Figure 2 shows where each of the three possible long-run regimes occurs in the $\{\theta, \nu\}$ plane. The numerical values corresponding to points $\mathrm{A}, \mathrm{B}$, and $\mathrm{C}$ are presented in Table 1.

The benchmark regime arises when $\nu$ and $\theta$ are small enough (from Conditions (12) and (13)). Since, in the numerical example, the two types of capital have the same depreciation and productivity parameters $\left(\delta_{H}=\delta_{K}\right.$ and $\left.\beta=\epsilon\right)$, the optimal capital ratio $h / k$ is equal to one in this regime, as is the optimal investment ratio $g / i$. Point A represents such a situation. Assuming the same low political weight attached to rent-seekers $(\theta=1 / 4)$ but increasing the efficiency of the corruption technology $\nu$, the economy switches to a regime where corruption is still absent, but public investment is distorted (point B). As highlighted by the analytical results, the government reduces the investment subject to corruption in order to lower the income from rent-seeking and prevent corruption from occurring at equilibrium. The ratio of public spending $g / i$ is now equal to 1.19 , reflecting that the possibility that corruption distorts the composition of public spending in favor of investment for which rent-seeking is not possible. This distortion entails a loss of productive efficiency, as reflected in the lower 


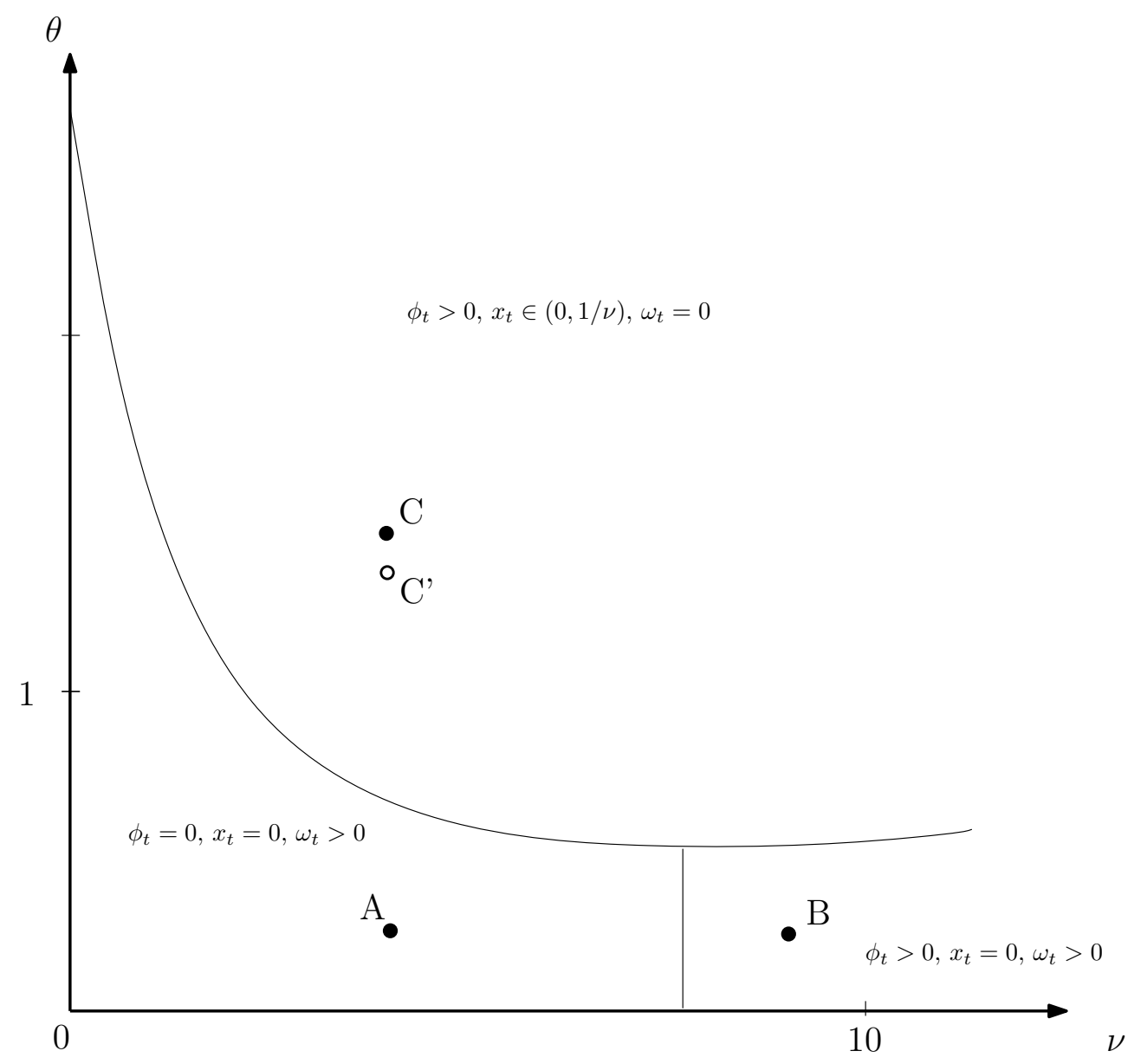

Figure 2: Regime zones in the $\{\theta, \nu\}$ plane

\begin{tabular}{llllllllll}
\hline \hline & $\nu$ & $\theta$ & $\phi$ & $x$ & $g$ & $i$ & $g / i$ & $h / k$ & $y$ \\
\hline $\mathrm{A}$ & 4 & $1 / 4$ & 0 & 0 & 0.37 & 0.37 & 1 & 1 & 2.13 \\
$\mathrm{~B}$ & 9 & $1 / 4$ & 0.015 & 0 & 0.36 & 0.30 & 1.19 & 1.19 & 2.04 \\
$\mathrm{C}$ & 4 & $3 / 2$ & 0.262 & 0.20 & 0.24 & 0.54 & 0.45 & 2.02 & 1.38 \\
\hline \hline
\end{tabular}

Table 1: Steady state comparisons 

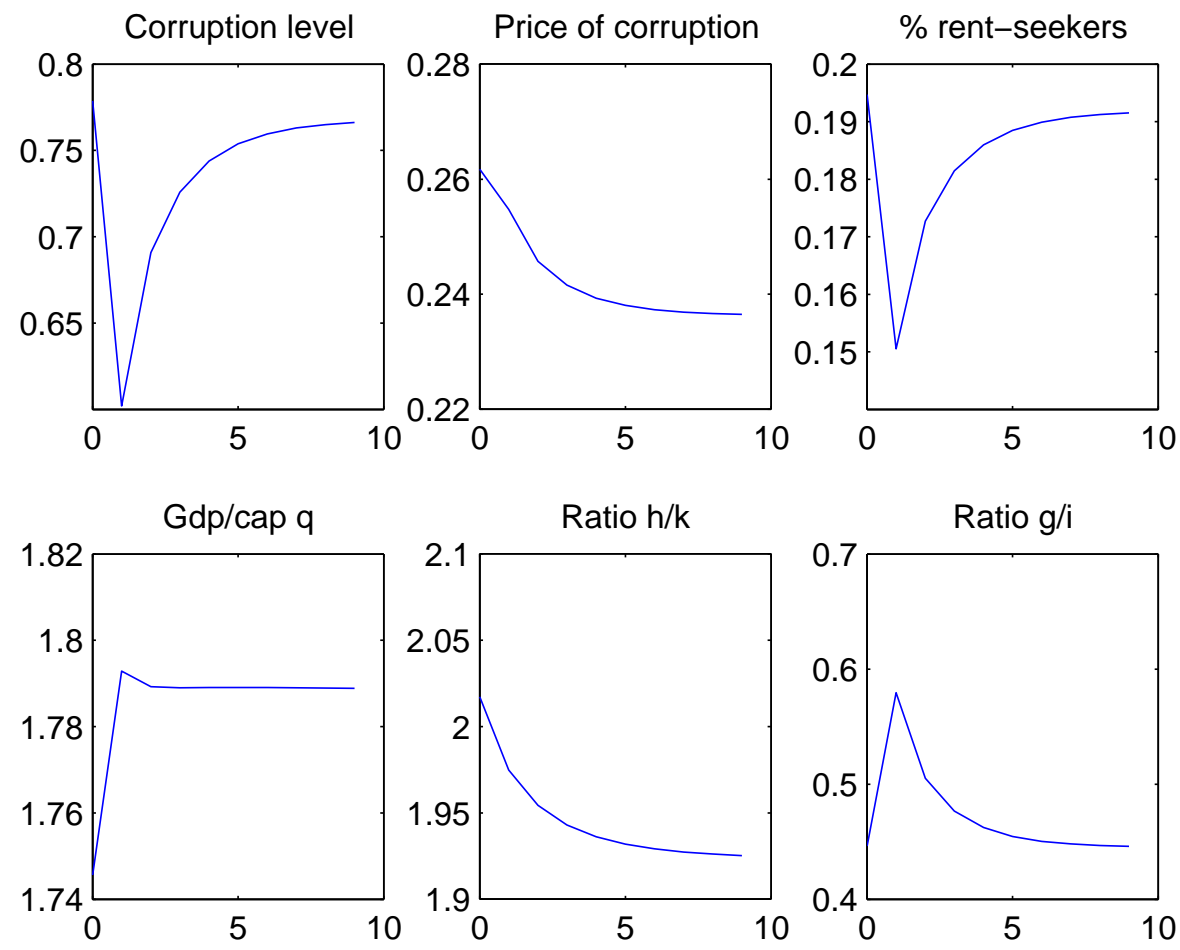

Figure 3: Transition from $\mathrm{C}$ to $\mathrm{C}$ ' with a permanent drop in $\theta$

value of income per capita $y$.

The interior regime arises for high values of $\theta$. In this case, for example at point $\mathrm{C}$, the rent-seekers have such a high political weight that public spending subject to corruption is encouraged. The ratio $g / i$ is equal to 0.45 . Notice that this does not imply that capital $h$ is low compared to $k$ because the major part of the investment in $k$ does not reach its target. In fact, both capital stocks are lower than in the economy without corruption, but the ratio $h / k$ is higher. As a consequence of low investment levels and distorted allocation, output per person $y$ is lower than in the two previous cases.

In order to illustrate the dynamic behavior of the economy and check for the local stability of the steady state, consider steady state C. Assume that there is a permanent unanticipated change in one parameter, say a decrease in $\theta$ from 1.5 to 1.375 . The new steady state is represented by point C'. The dynamics around C' can be represented by a system of four first-order difference equations with two pre-determined variables $k$ and $h$. The eigenvalues of the linearized system around C' are 0.5553, 0.849, 1.227, and 1.876, indicating that $\mathrm{C}^{\prime}$ is a stable saddle-point (the Blanchard-Kahn conditions 
are satisfied). Hence there is a unique trajectory converging to the steady state. To simulate the transition from one steady state to one another, we use the method developed by Boucekkine (1995) and Juillard (1996). Figure 3 represents the transition path. ${ }^{6}$ We observe that the control variables (\% rent seekers, corruption level, ratio $g / i)$ rise on the new saddle path at the time of the shock, and then converge slowly to the new steady state. The predetermined variable (ratio $h / k$ ) adjusts monotonically to the new steady state. The price of corruption, computed from (18), and GDP per capita are functions of both control (jump) and state variables. The effect of the decrease in $\theta$ is to decrease corruption, mostly in the short run, but to increase GDP per capita permanently. In the long-run, the investment ratio returns to its initial level, but the ratio of the capital stocks $k / h$ is now higher, because less investment spending on $k$ has been diverted by rent-seekers.

\section{Empirical Analysis}

In our model, the composition of public investment is endogenous and depends on a set of parameters. Theory suggests that the way this ratio is affected by the different parameters is not the same in the three main regimes described above. The different kinds of steady states we have identified can be mapped into development levels. High income $(y)$ countries are more likely to be either in the benchmark regime (if the predatory technology $(\nu)$ and the concentration of power $(\theta)$ are low), or in the regime with distortion but no corruption (if they have a more efficient predatory technology (higher $\nu$ ) but still a well distributed political power (low $\theta$ )). In this latter case, there is no corruption at equilibrium, but public spending is biased towards those for which corruption is more difficult. Developing countries are more likely to be in the interior regime, with high $\nu$ and $\theta$, widespread corruption and public spending biased towards areas in which corruption is easier.

Hence a clearcut prediction of our theory is that a rise in corruption technology entails a rise in the investment ratio $g / i$ for developed countries in the regime with distortion but no corruption, but a fall in the investment ratio $g / i$ for developing countries (interior regime).

In this section, we present observed variables which correspond to these parameters and investigate their effects on the ratio of public investment. We will introduce interaction

\footnotetext{
${ }^{6}$ The difference between the simulated path and the constant solution should be interpreted as the difference between an economy which has experienced such a shift and one which has not.
} 
terms between the variables measuring $\nu$ and $\theta$ and initial development levels in order to test the key prediction highlighted above.

\subsection{Measurement}

The four parameters $\nu, \theta, \rho, n$ and productivity $\Gamma[$.$] are measured with the following$ variables. Descriptive statistics of all the variables and the list of countries used in the econometric analysis are provided in Appendix B (see Tables 3, 4 and 5). Since the variables are imperfect measures of the parameters and since there might be simultaneity, we may face endogeneity biases. We also present the instruments we use to control for endogeneity.

1. Techcor: The effect of $\nu$ is estimated by using the Rule of Law index available in the Governance Research Indicator Country Snapshot (GRICS). This index is an aggregate of perceptions of the incidence of crime, of the effectiveness and predictability of the judiciary, and of the enforceability of contracts. To use this index as a proxy for $\nu$, we assume that the technology of corruption is as efficient as the legal (penal and judicial) system is inefficient (Becker and Stigler (1974); Jacquemet (2006)). Therefore, we operate the following transformation: Techcor $=2.5-$ Rule of Law, so that Techcor varies between 0 and 5. Hence, the higher the variable Rule of Law, the higher is the probability of a corrupt public agent being caught and punished, and the smaller the technology of corruption (Techcor). On the contrary, the lower the value of Rule of Law, the easier it is for rent-seekers to have recourse to corruption and the higher the value of Techcor.

2. Polbias: As a proxy for $\theta$, that is the political weight given to rent-seekers in the objective function, we use an indicator of the lack of political rights taken from Freedom House. Few political rights for the population indicate a strong concentration of power in the hands of a few. And those who hold the power are presumably rent-seekers (because of purchasing votes as mentioned above). Hence, if political rights are weak, rent-seekers concentrate power, which means $\theta$ is high. We subtract 1 from the original index in order to obtain a variable ranging from 0 (if the country provides very extended political rights to its citizens) to 7 (if the citizens have no political rights).

3. Patience: This variable indicates the number of years the party of the chief 
executive has been in office, ${ }^{7}$ taken from the Database of Political Institutions (Beck et al. 2001). It is used as a proxy for the discount factor $\rho$. We assume that political groups anticipate their term of office relatively well. Thus, if the political group has been in power for a long time, it is considered more patient and values the future more than parties who have been in power for a shorter period.

4. Pop: The rate of growth of the total population, taken from the World Development Indicators (WDI) database, stands for $n$.

5. $\boldsymbol{\Gamma}[$.$] : We use a first dummy variable (Tropic) which is equal to 1$ if the country is located between the tropic of Cancer and the tropic of Capricorn, 0 otherwise; and a second one (Ldlock) equal to 1 for landlocked countries, and to 0 otherwise. This enables us to control for geographic conditions affecting productivity $\Gamma[$.$] .$ These two variables are taken from the Global Development Network Growth Database, edited by the Development Research Institute of New York University.

To control for initial conditions, we introduce the logarithm of the 10 year-lagged constant PPP GDP per capita, $\ln \mathbf{Y}_{\mathbf{0}}$ which is provided by the WDI database.

The endogenous variable is measured by Ratio: $g / i$ relates public investment spending free from corruption to investment spending subject to corruption. $g$ is the proportion of health and education spending in total public expenditure. Expenditure on these two sectors has been shown to decrease with the extent of corruption (Mauro (1998); Gupta, Davoodi, and Alonso-Terme (2002); Delavallade (2006)). That does not mean that the education and health sectors are free from corruption (see, for example, Reinikka and Svensson (2004)) but that corruption in these sectors is less beneficial for top-ranking officials and politicians who decide the budgetary allocation. $i$ covers expenditure on housing, fuel and energy, agriculture, mining and manufacture, transport (and other economic activities) as a percentage of total government spending. ${ }^{8}$ The proportion of total public spending in each sector is taken from Government Finance Statistics Yearbooks provided by the International Monetary Fund. For checking robustness, we try alternative measures of $g$ and $i$ in Section 4.2. When data are missing, we use the

\footnotetext{
${ }^{7} \mathrm{~A}$ "forward-looking" variable indicating how many years would elapse before the next elections would have fitted better with the discount factor but, to the best of our knowledge, it is not available.

${ }^{8}$ In a sequel to this paper we will also investigate results with $g$ composed only of education spending, and with expenditure on defense, and culture and recreation included in $i$.
} 
figures for the following (odd) year when they are available. If not, we use the mean of the ratio for a given country.

\subsection{Estimation Results}

Using an instrumental variables regression, we estimate an equation where the endogenous variable is a function of the instrumented parameters and initial conditions. From theory we know that the benchmark regime and the regime with distortion but no corruption are more likely to fit developed countries whereas the interior regime (with corruption) corresponds to developing countries. To control for the possibility that the values of parameters $\nu$ and $\theta$ may differ according to the initial level of GDP, we add interaction terms to the list of regressors: $\frac{\text { Techcor }}{\ln Y_{0}}$ and $\frac{\text { Polbias }}{\ln Y_{0}}$.

The estimated equation is thus:

$$
\begin{aligned}
\text { Ratio }_{i t}=\alpha_{1} & +\alpha_{2} \text { Techcor }_{i t}+\alpha_{3}{\frac{\text { Techcor }}{\ln Y_{0}}}_{i t}+\alpha_{4} \text { Polbias }_{i t}+\alpha_{5}{\frac{\text { Polbias }}{\ln Y_{0}}}_{i t} \\
& +\alpha_{6} \text { Patience }_{i t}+\alpha_{7} \text { Pop }_{i t}+\alpha_{8} \text { Tropic }_{i t}+\alpha_{9} \text { Ldlock }_{i t}+\alpha_{10} \ln Y_{0 i t}+\varepsilon_{i t} .
\end{aligned}
$$

Estimates are run on even-year data $^{9}$ for the period 1996-2004 on 62 countries using a two-stage least squares (2sls) procedure. We first estimate an unrestricted model. At each step, we perform a Wald test that the least significant parameter of each equation is null. If the p-value of a coefficient is over 0.15 , we reject the coefficient at the following step. Hence, at the end of the procedure, we retain a restricted model for which all coefficients have a low p-value (below 0.15).

As mentioned above, the variables Techcor, Polbias and Patience suffer from substantial measurement error with respect to the actual technology of corruption, the lack of political rights and the discount factor. Hence, to reinforce the treatment of endogeneity, we introduce external instrumental variables which are used in the first stage of the procedure to provide predicted values of endogenous variables, then considered as their instrumented values. ${ }^{10}$ These excluded instruments are defined as follows:

1. antiq is an index of the depth of experience of state-level institutions, or state

\footnotetext{
${ }^{9}$ The Rule of Law index is only available from the World Bank for even years.

${ }^{10}$ The results of this first-stage regression are presented in Table 6 in Appendix C.
} 
antiquity. It was developed by Bockstette, Chanda, and Putterman (2002) $)^{11}$ and we use it here as an instrument for political and legal infrastructure. We also use the same index adjusted by a mobility matrix estimating for each country the proportion of the ancestors in 1500 of that country's population today that were living within what are now the borders of the country, provided by Putterman and Weil (2007).

2. yrind stands for the logarithm of the number of years of independence of the state. It measures the autonomy of the political and legal system and its capacity to influence or resist foreign influence.

3. legsoc, legfr and legbr are dummies equal to 1 if the country's legal system has a socialist, a French or a British origin respectively. ${ }^{12}$

4. polbiaslag is the ten-year lagged index of political rights.

5. poplag is ten-year lagged index of growth rate of the population.

6. natres is the percentage of natural-resource exports in GDP one year earlier. Natural resources include agricultural raw materials, fuel, food, ores and metals. This index is often used as an instrument for the level of corruption since abundant natural resources create strong incentives to rent-seeking, and hence to corruption (Leite and Weidmann 1999). The exploitation of natural resources strengthens corruption via its impact on the predatory technology, $\nu$ : we expect the technology of corruption to be more developed when the index of naturalresource exports is high. However, these exports being given as a percentage of GDP, we suspect this instrument of being too endogenous.

We perform two tests for evaluating the validity of using instrumented estimations. The first one is a Sargan overidentification test ${ }^{13}$ of the correlation of instrumental variables with error terms. If the null hypothesis is not rejected, the instruments are not correlated with the error terms, i.e. the instruments are not invalid. Second, we test whether the instruments are strong or weak, i.e. whether the instruments predict the endogenous regressors well or not. Traditionally, the first-stage $F$ test is used to do this.

\footnotetext{
${ }^{11}$ The index was developed from the answers for each country to the following three questions for each period of 50 years: a) Was there a government above the tribal level? b) Was this government foreign or locally based? c) How much of the territory of the modern country was ruled by this government?

${ }^{12}$ These indicators are available on New York University's web site.

${ }^{13}$ See Sargan (1958).
} 
Table 2: From the unrestricted to the restricted model: a three-step procedure

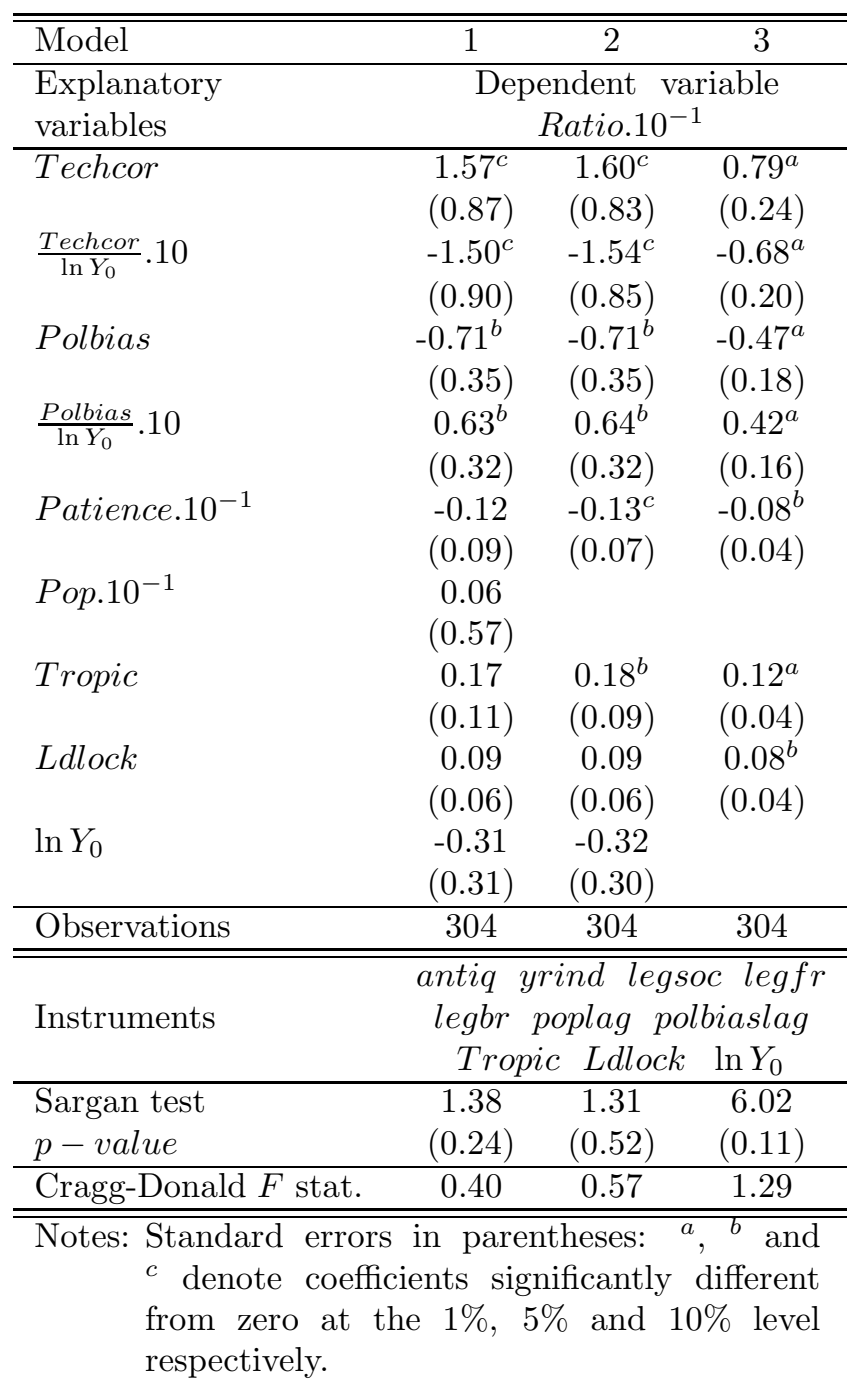

Staiger and Stock (1997) suggest that an F statistic exceeding 10 enables inference from instrumented estimations. But recent literature argues that in the presence of multiple endogenous regressors, the first-stage $F$ test is not sufficient and is less powerful than a test based on the Cragg-Donald (CD) F statistic (see Cragg and Donald (1993), Stock and Yogo (2002) and Stock, Wright, and Yogo (2002)). Hence, we provide a test of the null hypothesis that the instruments are weak using the CD $F$ statistic (for critical values, see Stock and Yogo (2002)). These two tests are presented at the bottom of Table 2. We also report the $t$-statistics associated with the coefficients of the instrumental variables in the first-stage regressions in Appendix $\mathrm{C}$ (see Table 6). 


\section{Interpretation and Robustness}

\subsection{Interpretation of the Results}

The two tests run on the instruments lead us to think that these instruments are valid. The results of Sargan's overidentification test reveal that the instruments are not significantly correlated with error terms. ${ }^{14}$ However, when substituting the adjusted state antiquity index to the raw one, the null hypothesis that instruments are not correlated with error terms has to be rejected. As for the second-stage results, they are not modified by such a substitution. Hence, we use the raw index of state antiquity and our instruments are valid insofar as they only affect the dependent variables through explanatory variables. Whether our instruments are strong or weak is less clear cut. For computational issues, the critical values corresponding to 6 endogenous regressors have not been tabulated. But, by extrapolating from those tabulated for 1, 2 and 3 endogenous variables (see Stock and Yogo (2002)), we are able to comment on the values of the CD F statistic. The first stage regression provides quite low values of the CraggDonald $F$ statistic (1.29), which indicates that some combinations of the coefficients might be badly identified (because of multicollinearity between the instruments and between the instrumented variables). Hence, inferences based on the coefficients might not be strictly valid (Stock and Wright 2000) and, in particular, counterfactuals might not be fully reliable. However, when the multicollinearity between the instrumented variables is reduced by dropping $\frac{T e c h c o r}{\ln Y_{0}}$ and $\frac{\text { Polbias }}{\ln Y_{0}}$ from the calculation of the CraggDonald $F$ statistic $^{15}$, it rises up to 7.08. Given that, for 3 endogenous variables and $7 / 8$ excluded instruments, the critical values are 4.44/4.46 for a 5\% significance level, our instruments can be considered as strong. On the other hand, high values of $t$ statistics (see Table 6 in Appendix C) show that the instrumental variables are individually significant. Thus, if some linear combinations of coefficients are badly identified, some others are well identified, the confidence intervals of the coefficients are reliable and our instruments are not irrelevant.

The first stage regressions of the endogenous regressors on instrumental variables presented in Table 6 suggest a few commentaries. First, the state antiquity reinforces the predatory technology and the lack of democracy. At the same time, states which

\footnotetext{
${ }^{14}$ The $p$-value of 0.24 associated with the test statistic in the first column should be read as follows: if the null hypothesis is true, i.e. if the instruments and the error terms are not correlated, we would obtain a test statistic at least as high as 1.38 in 24 estimations out of 100 .

${ }^{15}$ For the purpose of this calculation of the Cragg-Donald statistic we treat these interaction terms as exogenous regressors.
} 
became independent more recently tend to have weaker legal systems (favoring corruption) and to be weaker democracies. Indeed, when the state was colonized for a long time, a deeper experience of state-level institutions may strengthen mechanisms aiming at circumventing the legal system as well as authoritarian regimes which flout citizens' political rights. But a longer experience of independent state and autonomy helped build a stronger political and legal system. As regards to the origin of the legal system, our results are in line with legal origins theory comparing noticeably the effects of common law and civil law (La Porta et al. 1998), (Beck and Levine 2003). Indeed, legal systems with a French or Socialist origin provide significantly less efficient legal regimes (in particular to protect property rights) than those of British origin.

Let us now comment on the estimated coefficients in Table 2. As interaction terms with coefficients $\alpha_{3}$ and $\alpha_{5}$ are included in the regressions, the partial effects of Techcor and Polbias on the ratio $g / i$, when both single and interaction terms are significant, are given by $\alpha_{2}+\alpha_{3} / \ln Y_{0 i}$ and $\alpha_{4}+\alpha_{5} / \ln Y_{0 i}$ respectively for each country $i$. Figures 4 and 5 display the value of these derivatives from the coefficients estimated in equation (3) for the relevant range of $\ln Y_{0 i}$, from $\min \ln Y_{0}=6.18$ to $\max \ln Y_{0}=10.57$.

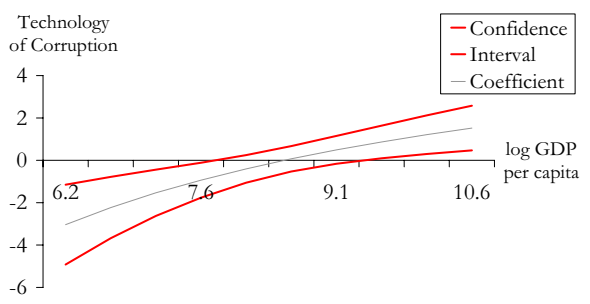

Figure 4: Partial effect of $\nu$ on ratio $g / i$

The results presented in Table 2 reveal first that the ratio of spending $g / i$ is negatively affected by the technology of corruption in the poorest countries, but positively affected in the richest ones. Its coefficient is significant at the $1 \%$ level and it ranges between -3.04 and 1.09 according to the initial level of GDP: the negative effect of $\nu$ on $g / i$ gets stronger as the initial GDP decreases.

Figure 4 indicates that the 95\%-confidence interval contains both positive and negative values of $\frac{\partial(g / i)}{\partial \nu}$ for GDP per capita between $\$ 2700$ and $\$ 11000$, but only negative ones for GDP per capita lower than $\$ 2700$, and positive ones for initial GDP higher than $\$ 11000$. In low-income countries, easier access to corruption (or lesser punishment for corruption) increases the part of the budget dedicated to rent-generating spending 
(mostly physical-capital spending) at the expense of social spending (mostly on human capital). In middle-income countries, the impact of the technology of corruption on the ratio of spending $g / i$ is undetermined. In high-income countries, the higher the technology of corruption, the higher the social spending (free from corruption) relative to capital spending (subject to corruption).

The technology of corruption entails two opposite distortions according to the initial level of GDP per capita. This is in line with the main findings of the model. Indeed, given the effect of $\nu$ on $g / i$, richer countries may be in the regime with distortion but without corruption: easier access to corruption makes effective corruption more plausible. But, the outcome of probabilistic voting is near that of a benevolent social planner $(\theta \text { is low })^{16}$, so it reduces investment spending subject to corruption in order to lower the income from rent-seeking and prevent corruption. On the contrary, poorer countries seem to fit better with the interior regime with corruption and with distortion. Here, the government is more kleptocratic and corruption is not only potential but effective and distorts the structure of the budget in the opposite way, i.e. in favor of rent-generating spending.

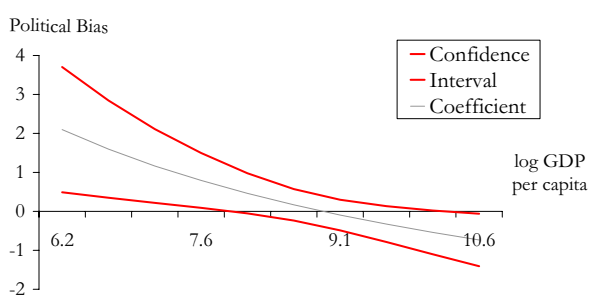

Figure 5: Partial effect of $\theta$ on ratio $g / i$

The variable lack of political rights (standing for $\theta$ ) has a coefficient between 2.1 and -0.5. Figure 5 also shows that countries can be divided into two categories according to the initial level of GDP per capita. In high- and middle-income countries (with a GDP per capita over $\$ 2700$ ) the effect of the concentration of political power is not significant. The short term effects described in Subsection 2.4 suggest a negative and significant coefficient, at least for high-income countries. The most democratic ones (with the lowest $\theta$ ) would distort the structure of public spending in favor of education and health

\footnotetext{
${ }^{16}$ The pairwise correlation coefficient between $\theta$ and initial GDP per capita is -0.64 and significant at the $1 \%$ level. However, when we introduce the interaction term $\nu \theta$, its coefficient is not significantly different from 0 . This might be due to high correlations with $\nu$ and $\theta$, which capture all the effect on the ratio of spending.
} 
(increasing $g / i$ ) to deter corruption, as exemplified by the regime with distortion but without corruption. On the other hand, in low-income countries, which experience the regime with corruption, $\theta$ has a significantly positive effect on the ratio $g / i$ : the more concentrated the power, the higher the proportion of government spending devoted to education and health. This positive coefficient contradicts the effects described in subsection 2.4. This might be due to "poverty reduction strategies" 17 developed by these countries which lead them to raise their expenditure on education and health policies. In this case, this variable can be considered as a proxy for such strategies, more common to countries lacking in political rights. Then, controlling for poverty reduction strategies, we can see that corruption increases rent-generating expenditure relatively to social expenditure.

Considering the combined effects of failing legal and political institutions, simulations show that if Zimbabwe had had Denmark's technology of corruption and index of democracy in 2004, that is 0.6 and 0 instead of 3.04 and 3 respectively, then its ratio of investment $g / i$ would be 1.91 instead of 1.22 . However, the low value of the Cragg-Donald $F$ statistic (1.29) indicates that the instruments are quite weak for the regression of $g / i$. As mentioned above, the results of simulations based on the regression of $g / i$ should be treated with care.

\subsection{Robustness Tests}

In this section, we perform robustness tests on the components of the ratio $g / i$ and on the set of instruments.

\subsubsection{Robustness to the definition of $g / i$}

We undertake sensitivity tests relative to the specification of the ratio $g / i$ of public investment. This is defined in Table 2 as $g / i$, where $g$ is composed of that part of public spending invested in education and health and $i$ is composed of expenditure on housing, fuel and energy, agriculture, mining and manufacture, transport and other economic activities as a percentage of total government expenditure. Table 7 in Appendix $\mathrm{C}$ reports the results of estimating Equation 3 in which $i$ includes expenditure on defense first (Equation 3.1), then expenditure on defense and culture (Equation 3.2) in addition to housing and economic activities. Indeed, the proportions of these sectors were shown

\footnotetext{
${ }^{17}$ Poverty reduction strategies are in place in most countries benefiting from foreign aid. They noticeably consist of reinforcing public investment in health and education.
} 
to be those likely to rise with increasing levels of public corruption (Delavallade 2006). The global effects of the predatory technology and the concentration of power on $g / i$, when $i$ includes the percentages of expenditure not only on economic activities and housing but also on defense, are similar to those observed for the main estimations. We note that the negative impact of a failing legal system, favoring corruption, on the ratio $g / i$ is a little less clear cut than in the main analysis. This finding is in line with Delavallade (2006) which shows that the lack of freedom, rather than the extent of corruption, strengthens the proportion of defense spending in the budget. On the other hand, the lack of democracy provides very similar results to those obtained for Equation 3. The significance of the coefficients has decreased very slightly but is still higher than $10 \%$. Thisimplies that defense and culture are also sectors subject to corruption, hence favored by a weak legal system and a strong concentration of power within rent-seekers, although a little less so than economic activities and housing.

Finally, in Equation 3.3, $\mathrm{g}$ is only composed of education expenditure. The estimated effects of the different explanatory variables are very close to those of the main model, as are the results of the relevance tests for instruments. This reinforces the robustness of the results presented above.

\subsubsection{Robustness to the choice of instruments}

We now provide a test of sensitivity to the set of instruments. The results are presented in the last column of Table 7. In Equation 3.4, we substitute the percentage of naturalresource exports in GDP for the ten-year lagged index of political rights. Estimates are very close to our main estimation. All the coefficients are significant at least at the $10 \%$ level and their values are very similar to the previous ones. Tests of validity of the instruments are satisfactory as well. A noticeable difference lies in the higher values of the Sargan test statistic when using natural-resource exports as an instrument, which indicates a higher correlation between the instruments and the error terms. We expected this instrument not to be valid because it was given as a percentage of GDP.

\section{Conclusion}

Corruption affects economic growth through many channels, one of them consisting of a modification of the structure of public expenditure in favor of specific types of spending. This distortion has not previously been clearly characterized. There is no theoretical 
study of the possible mechanisms through which this distortion could operate, and the empirical literature has been confined to estimating the effect of corruption on several types of public spending. In this paper we propose a coherent theoretical and empirical view of the effects of corruption on the allocation of public investment, their legal and political determinants and their impact on growth. We show that corruption leads to different kinds of budgetary distortions, more or less harmful to growth, according to the quality of the legal and political institutions and to the level of development.

In order to inspect the mechanisms linking corruption to public investment and growth, we provide an optimal growth model with endogenous rent-seeking. Households choose between being producers or rent-seekers. Voters choose the composition of public spending taking into account the behavior of households (incentive constraint). At equilibrium, the level of corruption, the ratio of spending and GDP per capita depend on the predatory technology and the concentration of power in rent-seekers' hands. We make several regimes, with and without corruption, at equilibrium explicit.

A contribution of our model is to show that the effect of corruption is not always the same: it may distort the distribution of public expenditure in two different ways. In both cases, this distortion hampers growth. The type of distortion depends on the extent to which political power is concentrated in the hands of rent-seekers. When power is strongly concentrated, a high predatory technology leads to high levels of actual corruption and distorts the structure of public spending in favor of investment in physical capital, at the expense of investment in human capital. On the contrary, in a more democratic regime, a greater technology of corruption make potential corruption higher but has no effect on its actual level; and it leads to an increase in expenditure in human capital relative to physical capital. Both types of distortion are harmful to growth but the former, with a strong concentration of political power, is the more detrimental.

The third contribution of this paper is to provide empirical evidence of the main implications of the model. We show that, in line with theory, the effect of a poor legal system on the structure of public investment varies with the level of development. In richer countries, when corruption is made possible by a failing legal system (i.e. which provides a well-developed predatory technology), public expenditure is distorted in favor of human capital spending, in order to discourage rent-seekers from corruption. In contrast, a failing legal system in a poor country entails a fall in the ratio of human capital to physical capital spending. 


\section{References}

Acemoglu, Daron. 1995. "Reward structures and the allocation of talent." European Economic Review 39:17-33.

Acemoglu, Daron, and Thierry Verdier. 2000. "The Choice between Market Failures and Corruption." American Economic Review 90 (1): 194-211.

Arrow, Kenneth, and Mordecai Kurz. 1970. Public Investment, the Rate of Return and Optimal Fiscal Policy. Baltimore: The Johns Hopkins University Press.

Banerjee, Abhijit V. 1997. "A Theory of Misgovernance." The Quarterly Journal of Economics 112 (4): 1289-1332.

Bardhan, Pranab K. 2006. "The Economist's Approach to the Problem of Corruption." World Development 34 (2):341-348.

Barro, Robert. 1990. "Government spending in a simple model of endogenous growth." Journal of Political Economy 98 (5): S103-S125.

Beck, Thorsten, George Clarke, Alberto Groff, Philip Keefer, and Patrick Walsh. 2001. "New tools in comparative political economy: The Database of Political Institutions." World Bank Economic Review 15 (1):165-176.

Beck, Thorsten, and Ross Levine. 2003, September. "Legal institutions and financial development." Policy research working paper series 3136, The World Bank.

Becker, Gary S., and George J. Stigler. 1974. "Law Enforcement, Malfeasance, and Compensation of Enforcers." The Journal of Legal Studies 3 (1):1-18.

Bernheim, Douglas, and Michael Whinston. 1986. "Menu Auctions, Resource Allocation, and Economic Influence." Quarterly Journal of Economics 101 (1): 1-31.

Bockstette, Valerie, Areendam Chanda, and Louis Putterman. 2002. "States and Markets: The Advantage of an Early Start." Journal of Economic Growth 7 (4): 347-69.

Boucekkine, Raouf. 1995. "An alternative methodology for solving non-linear forwardlooking models." Journal of Economic Dynamics and Control 19 (4): 711-734.

Coughlin, Peter, and Shmuel Nitzan. 1981. "Electoral Outcomes with Probabilistic Voting and Nash Social Welfare Maxima." Journal of Public Economics 15 (1): 113-21.

Cragg, John G, and Stephen G Donald. 1993. "Testing Identifiability and Specification in Instrumental Variable Models." Econometric Theory 9 (2): 222-40 (June). 
de la Croix, David, and Clara Delavallade. 2008. "Democracy, Rule of Law, Corruption Incentives and Growth." mimeo.

de la Croix, David, and Philippe Michel. 2002. A Theory of Economic Growth: Dynamics and Policy in Overlapping Generations. Cambridge: Cambridge University Press.

Delavallade, Clara. 2006. "Corruption and Distribution of Public Spending in Developing Countries." Journal of Economics and Finance 30 (2):222-239.

Docquier, Frederic, and Essaid Tarbalouti. 2001. "Bribing Votes: A New Explanation to the "Inequality-Redistribution" Puzzle in LDCs." Public Choice 108 (3-4): 25972 (September).

Gupta, Sanjeev, Hamid Davoodi, and Rosa Alonso-Terme. 2002. "Does corruption affect income inequality and poverty?" Economics of Governance 3 (1): 23-45 (03).

Gupta, Sanjeev, Raju Sharan, and Luiz de Mello. 2000, February. "Corruption and Military Spending." Imf working papers 00/23, International Monetary Fund.

Jacquemet, Nicolas. 2006. "Micro-conomie de la corruption." Revue Franaise d'Economie XX (4):118-159.

Juillard, Michel. 1996. "A program for the resolution and simulation of dynamic models with forward variables through the use of a relaxation algorithm." Technical Report 9602, CEPREMAP, Paris.

Kanczuk, Fabio. 1998. "The political economy of poverty trap." UCLA Ph.D Thesis.

La Porta, Rafael, Andrei Shleifer, Robert W. Vishny, and Florencio Lopez de Silanes. 1998. "Law and Finance." Journal of Political Economy 106 (6):1113-1155.

Leite, Carlos, and Jens Weidmann. 1999. "Does Mother Nature Corrupt - Natural Resources, Corruption, and Economic Growth." Imf working papers 99/85, International Monetary Fund.

Mariani, Fabio. 2006. "Migration as an antidote to rent-seeking?" mimeo.

Mauro, Paolo. 1997. Chapter The Effects of Corruption on Growth, Investment and Government Expenditure of Corruption and the Global Economy, edited by K. Elliot, 83-108.

- 1998. "Corruption and the composition of government expenditure." Journal of Public Economics 69 (2): 263-279 (June). 
McKenzie, Lionel. 1986. "Optimal economic growth, turnpike theorems and comparative dynamics." Chapter 26 of Handbook in Mathematical Economics, edited by Kenneth Arrow and Michael Intriligator, 1281-1355. Amsterdam: North-Holland.

Persson, Torsten, and Guido E. Tabellini. 2000. Political Economics: Explaining Economic Policy. Cambridge, Massachusetts: MIT Press.

Putterman, Louis, and David N. Weil. 2007. "Post-1500 Population Flows and the Long Run Determinants of Economic Growth and Inequality." mimeo.

Reinikka, Ritva, and Jakob Svensson. 2004. "The Power of Information: Evidence from Public Expenditure Tracking Surveys." Global Corruption Report 2004. Transparency International.

Sargan, J. 1958. "The estimation of economic relationships using instrumental variables." Econometrica 26 (3):393-415.

Shleifer, Andrei, and Robert W Vishny. 1993. "Corruption." The Quarterly Journal of Economics 108 (3): 599-617.

Solow, Robert. 1956. "A contribution to the theory of economic growth." Quarterly Journal of Economics 70 (1): 65-94.

Staiger, Douglas, and James H. Stock. 1997. "Instrumental Variables Regression with Weak Instruments." Econometrica 65 (3): 557-586 (May).

Stock, James H., and Jonathan Wright. 2000. "GMM with Weak Identification." Econometrica 68 (5): 1055-1096 (September).

Stock, James H., and Motohiro Yogo. 2002, November. "Testing for Weak Instruments in Linear IV Regression." Nber technical working papers 0284, National Bureau of Economic Research, Inc.

Stock, James H, Jonathan H Wright, and Motohiro Yogo. 2002. "A Survey of Weak Instruments and Weak Identification in Generalized Method of Moments." Journal of Business \& Economic Statistics 20 (4): 518-29 (October).

Tanzi, Vito. 1998. "Corruption Around the World: Causes, Consequences, Scope, and Cures." IMF Staff Papers 45 (4): 1. 


\section{A Solution to the Voting Problem}

We follow McKenzie (1986) and de la Croix and Michel (2002) and use the Lagrangian of period $t \mathcal{L}_{t}$, which has the interest of being simpler and more intuitive (and yielding the same results as the infinite Lagrangian). The Lagrangian $\mathcal{L}_{t}$ is composed of the terms of the infinite Lagrangian which depends on $h_{t}, g_{t}, k_{t}, i_{t}$ and $x_{t}$. Replacing $W_{t}$ by its value from $(7), U_{t}$ by its value from $(3)$ and $V_{t}=u\left[\nu i_{t}-g_{t}-i_{t}\right]$, we obtain:

$$
\begin{aligned}
& \mathcal{L}_{t}=\left(1-x_{t}\right) u\left[\Gamma\left[1-x_{t}\right] f\left[h_{t}, k_{t}\right]-g_{t}-i_{t}\right]+(1+\theta) x_{t} u\left[\nu i_{t}-g_{t}-i_{t}\right] \\
& +\rho \lambda_{t+1}\left[\left(1-\delta_{H}\right) h_{t}+g_{t}\right]-\lambda_{t}(1+n) h_{t} \\
& +\rho \mu_{t+1}\left[\left(1-\delta_{K}\right) k_{t}+\left(1-\nu x_{t}\right) i_{t}\right]-\mu_{t}(1+n) k_{t} \\
& +\phi_{t}\left(\Gamma\left[1-x_{t}\right] f\left[h_{t}, k_{t}\right]-\nu i_{t}\right)+\omega_{t} x_{t}
\end{aligned}
$$

It is equal to the instantaneous utility plus the increase in the value of the two capital stocks, $\rho \lambda_{t+1} h_{t+1}-\lambda_{t}(1+n) h_{t}$ and $\rho \mu_{t+1} k_{t+1}-\mu_{t}(1+n) k_{t}$ minus the cost of the inequality constraints. For an optimal solution, the derivatives of $\mathcal{L}_{t}$ with respect to the five variables are zero:

$$
\begin{gathered}
\frac{\partial \mathcal{L}_{t}}{\partial h_{t}}=\begin{array}{c}
\left(\left(1-x_{t}\right) u^{\prime}\left[y_{t}\right]+\phi_{t}\right) \Gamma\left[1-x_{t}\right] f_{H}^{\prime}\left[h_{t}, k_{t}\right] \\
\quad+\rho\left(1-\delta_{H}\right) \lambda_{t+1}-(1+n) \lambda_{t}=0
\end{array} \\
\begin{array}{cc}
\frac{\partial \mathcal{L}_{t}}{\partial g_{t}}= & -\left(1-x_{t}\right) u^{\prime}\left[y_{t}\right]-(1+\theta) x_{t} u^{\prime}\left[\nu i_{t}-g_{t}-i_{t}\right]+\rho \lambda_{t+1}=0 \\
\frac{\partial \mathcal{L}_{t}}{\partial k_{t}}=\left(\left(1-x_{t}\right) u^{\prime}\left[y_{t}\right]+\phi_{t}\right) \Gamma\left[1-x_{t}\right] f_{K}^{\prime}\left[h_{t}, k_{t}\right] & +\rho\left(1-\delta_{K}\right) \mu_{t+1}-(1+n) \mu_{t}=0 \\
\frac{\partial \mathcal{L}_{t}}{\partial i_{t}}= & -\left(1-x_{t}\right) u^{\prime}\left[y_{t}\right]+(1+\theta)(\nu-1) x_{t} u^{\prime}\left[\nu i_{t}-g_{t}-i_{t}\right]+\rho \mu_{t+1}\left(1-\nu x_{t}\right) \\
\frac{\partial \mathcal{L}_{t}}{\partial x_{t}}= & -u\left[y_{t}\right]+(1+\theta) u\left[\nu i_{t}-g_{t}-i_{t}\right]-\nu \rho \mu_{t+1} i_{t} \\
-\left(\left(1-x_{t}\right) u^{\prime}\left[y_{t}\right]+\phi_{t}\right) \Gamma^{\prime}\left[1-x_{t}\right] f\left[h_{t}, k_{t}\right]+\omega_{t}=0
\end{array}
\end{gathered}
$$

with

$$
y_{t}=\Gamma\left[1-x_{t}\right] f\left[h_{t}, k_{t}\right]-g_{t}-i_{t} .
$$


The multipliers of the inequality constraints should satisfy:

$$
\begin{aligned}
\phi_{t} & \geq 0 \\
\phi_{t}\left(\Gamma\left[1-x_{t}\right] f\left[h_{t}, k_{t}\right]-\nu i_{t}\right) & =0 \\
\nu i_{t} & \leq \Gamma\left[1-x_{t}\right] f\left[h_{t}, k_{t}\right] \\
\omega_{t} & \geq 0 \\
\omega_{t} x_{t} & =0 \\
-x_{t} & \leq 0
\end{aligned}
$$

The transversality conditions are:

$$
\lim _{t \rightarrow \infty} \rho^{t} \lambda_{t} h_{t}=0, \quad \text { and } \quad \lim _{t \rightarrow \infty} \rho^{t} \mu_{t} k_{t}=0 .
$$

\section{Benchmark Regime}

We first consider the regime where $x_{t}=0, \phi_{t}=0$, and $\omega_{t}>0$. Equation (4) holds and the incentive constraint is not binding. There is no corruption and public investment is not distorted. The first order conditions become

$$
\begin{aligned}
& \frac{\partial \mathcal{L}_{t}}{\partial h_{t}}=u^{\prime}\left[y_{t}\right] \Gamma[1] f_{H}^{\prime}\left[h_{t}, k_{t}\right]+\rho\left(1-\delta_{H}\right) \lambda_{t+1}-(1+n) \lambda_{t}=0 \\
& \frac{\partial \mathcal{L}_{t}}{\partial g_{t}}=-u^{\prime}\left[y_{t}\right]+\rho \lambda_{t+1}=0 \\
& \frac{\partial \mathcal{L}_{t}}{\partial k_{t}}=u^{\prime}\left[y_{t}\right] \Gamma[1] f_{K}^{\prime}\left[h_{t}, k_{t}\right]+\rho\left(1-\delta_{K}\right) \mu_{t+1}-(1+n) \mu_{t}=0 \\
& \frac{\partial \mathcal{L}_{t}}{\partial i_{t}}=-u^{\prime}\left[y_{t}\right]+\rho \mu_{t+1}=0 \\
& \frac{\partial \mathcal{L}_{t}}{\partial x_{t}}=-u\left[y_{t}\right]+(1+\theta) u\left[\nu i_{t}-g_{t}-i_{t}\right]-\nu \rho \mu_{t+1} i_{t}-u^{\prime}\left[y_{t}\right] \Gamma^{\prime}[1] f\left[h_{t}, k_{t}\right]+\omega_{t}=0
\end{aligned}
$$

First notice that $\lambda_{t+1}=\mu_{t+1}$. The Keynes-Ramsey rule can be derived by replacing $\lambda_{t}$ and $\lambda_{t+1}$ in the first equation by their value computed from the second equation.

$$
\begin{aligned}
\lambda_{t+1} & =u^{\prime}\left[y_{t}\right] / \rho \\
\frac{u^{\prime}\left[y_{t-1}\right]}{u^{\prime}\left[y_{t}\right]} & =\frac{\rho\left(\Gamma[1] f_{H}^{\prime}\left[h_{t}, k_{t}\right]+1-\delta_{H}\right)}{1+n}
\end{aligned}
$$


The relation between the marginal productivities of the two types of capital is derived by combining the Keynes-Ramsey rule derived above with the expression obtained by replacing $\mu_{t}$ and $\mu_{t+1}$ in the third equation by their value computed from the fourth equation.

$$
\begin{gathered}
\mu_{t+1}=u^{\prime}\left[y_{t}\right] / \rho \\
\rightarrow \\
1-\delta_{H}+\Gamma[1] f_{H}^{\prime}\left[h_{t}, k_{t}\right]=1-\delta_{K}+\Gamma[1] f_{K}^{\prime}\left[h_{t}, k_{t}\right] .
\end{gathered}
$$

which is equation (10) of the main text.

The last equation can be used to derive an expression for the multiplier $\omega_{t}$ :

$$
\omega_{t}=u\left[y_{t}\right]-(1+\theta) u\left[\nu i_{t}-g_{t}-i_{t}\right]+\nu \rho \mu_{t+1} i_{t}+u^{\prime}\left[y_{t}\right] \Gamma^{\prime}[1] f\left[h_{t}, k_{t}\right]
$$

Imposing $\omega_{t}>0$ on it gives an upper bound on the parameter $\theta$ :

$$
1+\theta<\frac{u\left[y_{t}\right]+\nu \rho \mu_{t+1} i_{t}+u^{\prime}\left[y_{t}\right] \Gamma^{\prime}[1] f\left[h_{t}, k_{t}\right]}{u\left[\nu i_{t}-g_{t}-i_{t}\right]}
$$

which is equation (11) of the main text.

\section{Distortion without Corruption}

This is regime where $x_{t}=0, \phi_{t}>0$, and $\omega_{t}>0$. This case corresponds to a situation without corruption, but where Equation (4) does not hold. When the incentive constraint holds with equality, $-u\left[y_{t}\right]+(1+\theta) u\left[\nu i_{t}-g_{t}-i_{t}\right]$ simplifies into $\theta u\left[y_{t}\right]$. The first order conditions are:

$$
\begin{aligned}
\frac{\partial \mathcal{L}_{t}}{\partial h_{t}} & =\left(u^{\prime}\left[y_{t}\right]+\phi_{t}\right) \Gamma[1] f_{H}^{\prime}\left[h_{t}, k_{t}\right]+\rho\left(1-\delta_{H}\right) \lambda_{t+1}-(1+n) \lambda_{t}=0 \\
\frac{\partial \mathcal{L}_{t}}{\partial g_{t}} & =-u^{\prime}\left[y_{t}\right]+\rho \lambda_{t+1}=0 \\
\frac{\partial \mathcal{L}_{t}}{\partial k_{t}} & =\left(u^{\prime}\left[y_{t}\right]+\phi_{t}\right) \Gamma[1] f_{K}^{\prime}\left[h_{t}, k_{t}\right]+\rho\left(1-\delta_{K}\right) \mu_{t+1}-(1+n) \mu_{t}=0 \\
\frac{\partial \mathcal{L}_{t}}{\partial i_{t}} & =-u^{\prime}\left[y_{t}\right]+\rho \mu_{t+1}-\phi_{t} \nu=0 \\
\frac{\partial \mathcal{L}_{t}}{\partial x_{t}} & =\theta u\left[y_{t}\right]-\nu \rho \mu_{t+1} i_{t}-\left(u^{\prime}\left[y_{t}\right]+\phi_{t}\right) \Gamma^{\prime}[1] f\left[h_{t}, k_{t}\right]+\omega_{t}=0
\end{aligned}
$$

From the second and fourth conditions, the shadow prices of capital are no longer 
equal:

$$
\lambda_{t+1}=\mu_{t+1}-\frac{\phi_{t} \nu}{\rho} .
$$

A modified Keynes-Ramsey rule can be derived by replacing $\lambda_{t}$ and $\lambda_{t+1}$ in the first equation by their value computed from the second equation.

$$
\begin{gathered}
\lambda_{t+1}=u^{\prime}\left[y_{t}\right] / \rho \\
\frac{u^{\prime}\left[y_{t-1}\right]}{u^{\prime}\left[y_{t}\right]}=\frac{\rho\left(\Gamma[1] f_{H}^{\prime}\left[h_{t}, k_{t}\right]+1-\delta_{H}\right)}{1+n}+\frac{\rho \Gamma[1] f_{H}^{\prime}\left[h_{t}, k_{t}\right]}{1+n} \frac{\phi_{t}}{u^{\prime}\left[y_{t}\right]}
\end{gathered}
$$

\section{Interior Regime: $0>x_{t}>1$ and $\phi_{t} \neq 0$}

This is the interior regime with $0<x_{t}<1 / \nu$. The multiplier $\phi_{t}>0$, but $\omega_{t}=0$. When the incentive constraint holds with equality, $-\left(1-x_{t}\right) u^{\prime}\left[y_{t}\right]+(1+\theta)(\nu-1) x_{t} u^{\prime}\left[\nu i_{t}-g_{t}-i_{t}\right]$ simplifies into $(\nu x(1+\theta)-(1+\theta x)) u^{\prime}\left[y_{t}\right]$, and $u^{\prime}\left[y_{t}\right]=u^{\prime}\left[\nu i_{t}-g_{t}-i_{t}\right]$. The first order conditions are:

$$
\begin{aligned}
& \frac{\partial \mathcal{L}_{t}}{\partial h_{t}}=\left(\left(1-x_{t}\right) u^{\prime}\left[y_{t}\right]+\phi_{t}\right) \Gamma\left[1-x_{t}\right] f_{H}^{\prime}\left[h_{t}, k_{t}\right]+\rho\left(1-\delta_{H}\right) \lambda_{t+1}-(1+n) \lambda_{t}=0 \\
& \frac{\partial \mathcal{L}_{t}}{\partial g_{t}}=-\left(1+\theta x_{t}\right) u^{\prime}\left[y_{t}\right]+\rho \lambda_{t+1}=0 \\
& \frac{\partial \mathcal{L}_{t}}{\partial k_{t}}=\left(\left(1-x_{t}\right) u^{\prime}\left[y_{t}\right]+\phi_{t}\right) \Gamma\left[1-x_{t}\right] f_{K}^{\prime}\left[h_{t}, k_{t}\right] \\
&+\rho\left(1-\delta_{K}\right) \mu_{t+1}-(1+n) \mu_{t}=0 \\
&\left.\frac{\partial \mathcal{L}_{t}}{\partial i_{t}}=\nu x(1+\theta)-(1+\theta x)\right) u^{\prime}\left[y_{t}\right]+\rho \mu_{t+1}\left(1-\nu x_{t}\right)-\phi_{t} \nu=0 \\
& \frac{\partial \mathcal{L}_{t}}{\partial x_{t}}=\theta u\left[y_{t}\right]-\nu \rho \mu_{t+1} i_{t}-\left(\left(1-x_{t}\right) u^{\prime}\left[y_{t}\right]+\phi_{t}\right) \Gamma^{\prime}\left[1-x_{t}\right] f\left[h_{t}, k_{t}\right]=0
\end{aligned}
$$

From the second and fourth conditions, the shadow prices of capital are no longer equal:

$$
\left(1-\frac{\nu x_{t}(1+\theta)}{1+\theta x_{t}}\right) \lambda_{t+1}=\mu_{t+1}\left(1-\nu x_{t}\right)-\frac{\phi_{t} \nu}{\rho} .
$$

The shadow price of corruption can be computed by solving the fifth equation for $\phi_{t}$ :

$$
\phi_{t}=\frac{\theta u\left[y_{t}\right]-\nu \rho \mu_{t+1} i_{t}-\left(1-x_{t}\right) u^{\prime}\left[y_{t}\right] \Gamma^{\prime}\left[1-x_{t}\right] f\left[h_{t}, k_{t}\right]}{\Gamma^{\prime}\left[1-x_{t}\right] f\left[h_{t}, k_{t}\right]}
$$


The Keynes-Ramsey rule can be derived by replacing $\lambda_{t}$ and $\lambda_{t+1}$ in the first equation by their value computed from the second equation.

$$
\begin{gathered}
\lambda_{t+1}=\left(1+\theta x_{t}\right) u^{\prime}\left[y_{t}\right] / \rho \\
\frac{1+\theta x_{t-1}}{1+\theta x_{t}} \frac{u^{\prime}\left[y_{t-1}\right]}{u^{\prime}\left[y_{t}\right]}=\frac{\rho\left(\Gamma\left[1-x_{t}\right] f_{H}^{\prime}\left[h_{t}, k_{t}\right]+1-\delta_{H}\right)}{1+n}+\frac{\rho}{1+n} \frac{\phi_{t}}{u^{\prime}\left[y_{t}\right]} \frac{\Gamma\left[1-x_{t}\right]}{1-x_{t}} f_{H}^{\prime}\left[h_{t}, k_{t}\right]
\end{gathered}
$$

\section{B Descriptive Statistics}

Table 3 reports the list of countries in the study. In Table 4 we report the descriptive statistics of the variables used in the estimation. Table 5 provides the main statistics of the dependent variable Ratio.

Table 3: List of the countries studied

\begin{tabular}{lllll}
\hline \hline Argentina & China & Greece & Malaysia & Spain \\
Australia & Colombia & Iceland & Mauritius & Sri Lanka \\
Austria & Costa Rica & India & Mexico & Sweden \\
Bangladesh & Cyprus & Indonesia & Nepal & Syria \\
Belgium & Denmark & Iran & Netherlands & Thailand \\
Bolivia & Dominican Rep. & Ireland & New Zealand & Tunisia \\
Botswana & Egypt & Israel & Norway & Turkey \\
Brazil & El Salvador & Jamaica & Pakistan & Uganda \\
Burundi & Ethiopia & Kenya & Panama & United Kingdom \\
Cameroon & Fiji & Korea, Rep. & Papua New Guinea & United States \\
Canada & Finland & Lesotho & Peru & Uruguay \\
Chile & Germany & Madagascar & Philippines & Venezuela \\
& & & Singapore & Zambia \\
\hline \hline
\end{tabular}


Table 4: Summary statistics of the variables Used in the estimations

\begin{tabular}{lcccccc}
\hline \hline & Variable & Obs. & Mean & Std. Dev. & Min & Max \\
\hline Dep. Var. & Ratio & 304 & 1.63 & 1.08 & 0.10 & 7.13 \\
\hline Explanatory & Techcor & 304 & 2.08 & 1.04 & 0.26 & 4.00 \\
Variables & Polbias & 304 & 1.71 & 1.92 & 0 & 6 \\
& Patience & 304 & 10.32 & 12.62 & 1 & 71 \\
& Pop & 304 & 1.39 & 0.79 & -0.03 & 4.00 \\
& Tropic & 304 & 0.45 & 0.50 & 0 & 1 \\
& Ldlock & 304 & 0.13 & 0.33 & 0 & 1 \\
& ln $Y_{0}$ & 304 & 8.63 & 1.09 & 6.21 & 10.31 \\
\hline Instruments & antiq & 304 & 0.46 & 0.26 & 0.07 & 1 \\
& yrind & 304 & 4.63 & 0.89 & 3.30 & 7.71 \\
& legsoc & 304 & 0.02 & 0.13 & 0 & 1 \\
& legfr & 304 & 0.47 & 0.50 & 0 & 1 \\
& legbr & 304 & 0.38 & 0.49 & 0 & 1 \\
& polbiaslag & 304 & 1.94 & 1.94 & 0 & 6 \\
& poplag & 304 & 1.68 & 0.98 & -0.46 & 4.09 \\
& natres & 266 & 1387.69 & 1196.11 & 108.32 & 8020.70 \\
\hline \hline
\end{tabular}

Table 5: Yearly statistics of the dependent variable: ratio

\begin{tabular}{cccccc}
\hline \hline Year & Obs & Mean & Std. Dev. & Min & Max \\
1996 & 58 & 1.48 & 1.01 & 0.10 & 4.97 \\
1998 & 62 & 1.60 & 1.04 & 0.11 & 4.83 \\
2000 & 62 & 1.64 & 1.00 & 0.11 & 5.45 \\
2002 & 62 & 1.80 & 1.28 & 0.11 & 7.13 \\
2004 & 60 & 1.63 & 1.03 & 0.11 & 5.19 \\
\hline \hline
\end{tabular}




\section{Robustness of the Estimation Results}

Table 6: Relevance test

Do the instruments predict well the endogenous regressors?

\begin{tabular}{|c|c|c|c|c|c|c|}
\hline & Techcor & $\frac{\text { Techcor }}{\ln Y_{0}} \cdot 10$ & Polbias & $\frac{\text { Polbias }}{\ln Y_{0}} .10$ & Patience. $10^{-1}$ & Pop \\
\hline \multirow[t]{2}{*}{ antiq } & $0.26^{c}$ & 0.17 & $1.30^{a}$ & $1.35^{a}$ & $0.69^{b}$ & -0.14 \\
\hline & $(1.88)$ & (1.12) & $(3.97)$ & $(3.26)$ & $(2.08)$ & $(-1.21)$ \\
\hline \multirow[t]{2}{*}{ yrind } & $-0.16^{a}$ & $-0.12^{a}$ & $-0.36^{a}$ & $-0.32^{a}$ & $-0.27^{a}$ & -0.05 \\
\hline & $(-3.83)$ & $(-2.68)$ & $(-3.67)$ & $(-2.60)$ & $(-2.78)$ & $(-1.55)$ \\
\hline \multirow[t]{2}{*}{$\operatorname{legfr}$} & $0.61^{a}$ & $0.46^{a}$ & $0.58^{b}$ & 0.42 & $0.49^{b}$ & $0.20^{b}$ \\
\hline & $(6.14)$ & $(4.11)$ & $(2.42)$ & $(1.39)$ & $(2.03)$ & $(2.40)$ \\
\hline \multirow[t]{2}{*}{ legbr } & 0.16 & 0.07 & 0.30 & 0.27 & 0.28 & $0.22^{a}$ \\
\hline & $(1.60)$ & $(0.62)$ & $(1.26)$ & $(0.92)$ & $(1.15)$ & $(2.69)$ \\
\hline \multirow[t]{2}{*}{ legsoc. 10} & $0.10^{a}$ & $0.07^{b}$ & $0.34^{a}$ & $0.39^{a}$ & $0.46^{a}$ & -0.02 \\
\hline & $(3.67)$ & $(2.45)$ & $(5.27)$ & $(4.84)$ & (7.09) & $(-0.86)$ \\
\hline \multirow[t]{2}{*}{ poplag } & $0.11^{b}$ & $0.11^{b}$ & $0.67^{a}$ & $0.81^{a}$ & 0.16 & $0.51^{a}$ \\
\hline & $(2.45)$ & $(2.21)$ & $(6.25)$ & $(6.00)$ & (1.46) & $(13.84)$ \\
\hline \multirow[t]{2}{*}{ polbiaslag } & -0.02 & -0.01 & $0.41^{a}$ & $0.53^{a}$ & $0.33^{a}$ & -0.02 \\
\hline & $(-0.77)$ & $(-0.42)$ & $(7.52)$ & $(7.73)$ & $(5.97)$ & $(-1.30)$ \\
\hline \multirow[t]{2}{*}{ natres. $10^{-3}$} & $-0.06^{b}$ & $-0.07^{b}$ & -0.08 & -0.09 & $-0.19^{a}$ & 0.01 \\
\hline & $(-2.53)$ & $(-2.41)$ & $(-1.39)$ & $(-1.26)$ & $(-3.32)$ & $(0.46)$ \\
\hline \multirow[t]{2}{*}{ Ldlock } & $-0.23^{b}$ & -0.15 & -0.06 & 0.12 & $0.46^{c}$ & $-0.17^{b}$ \\
\hline & $(-2.25)$ & $(-1.32)$ & $(-0.23)$ & $(0.39)$ & $(1.85)$ & $(-2.00)$ \\
\hline \multirow[t]{2}{*}{ Tropic } & $0.51^{a}$ & $0.49^{a}$ & $-0.33^{c}$ & $-0.56^{b}$ & $0.90^{a}$ & -0.01 \\
\hline & $(6.59)$ & $(5.66)$ & $(-1.78)$ & $(-2.40)$ & $(4.80)$ & $(-0.16)$ \\
\hline \multirow[t]{2}{*}{$\ln Y_{0}$} & $-0.59^{a}$ & $-1.04^{a}$ & $-0.25^{b}$ & $-0.53^{a}$ & $0.77^{a}$ & $-0.20^{a}$ \\
\hline & $(-11.68)$ & $(-18.23)$ & $(-2.06)$ & $(-3.47)$ & $(6.25)$ & $(-4.71)$ \\
\hline Observations & 266 & 266 & 266 & 266 & 266 & 266 \\
\hline
\end{tabular}

Notes: T-statistics in parentheses: ${ }^{a},{ }^{b}$ and ${ }^{c}$ denote coefficients significantly not null respectively at the $1 \%, 5 \%$ and $10 \%$ level. 
Table 7: Robustness tests for the estimation of the reduced model

\begin{tabular}{|c|c|c|c|c|}
\hline & 3.1 & 3.2 & 3.3 & 3.4 \\
\hline Explanatory & \multicolumn{4}{|c|}{ Dependent Variables } \\
\hline Variables & Ratio. $10^{-1}$ & Ratio. $10^{-1}$ & Ratio. $10^{-1}$ & Ratio. $10^{-1}$ \\
\hline \multirow[t]{2}{*}{ Techcor } & $0.40^{a}$ & $0.37^{a}$ & $0.31^{a}$ & $1.03^{a}$ \\
\hline & $(0.14)$ & $(0.13)$ & $(0.12)$ & $(0.31)$ \\
\hline \multirow{2}{*}{$\frac{\text { Techcor }}{\ln Y_{0}} .10$} & $-0.33^{a}$ & $-0.31^{a}$ & $-0.26^{a}$ & $-0.84^{a}$ \\
\hline & $(0.12)$ & $(0.11)$ & $(0.10)$ & $(0.24)$ \\
\hline \multirow[t]{2}{*}{ Polbias } & $-0.25^{b}$ & $-0.23^{b}$ & $-0.16^{c}$ & $-0.68^{a}$ \\
\hline & $(0.11)$ & $(0.10)$ & $(0.09)$ & $(0.26)$ \\
\hline \multirow{2}{*}{$\frac{\text { Polbias }}{\ln Y_{0}} \cdot 10$} & $0.21^{b}$ & $0.19^{b}$ & $0.15^{c}$ & $0.58^{a}$ \\
\hline & $(0.09)$ & $(0.09)$ & $(0.08)$ & $(0.22)$ \\
\hline \multirow[t]{2}{*}{ Patience. $10^{-1}$} & -0.03 & -0.03 & $-0.04^{b}$ & $-0.09^{a}$ \\
\hline & $(0.02)$ & $(0.02)$ & $(0.02)$ & $(0.03)$ \\
\hline \multirow[t]{2}{*}{ Tropic } & $0.07^{a}$ & $0.06^{a}$ & $0.07^{a}$ & $0.10^{c}$ \\
\hline & $(0.03)$ & $(0.02)$ & $(0.02)$ & $(0.05)$ \\
\hline \multirow[t]{2}{*}{ Ldlock } & 0.03 & 0.03 & $0.04^{b}$ & $0.08^{c}$ \\
\hline & $(0.02)$ & $(0.02)$ & $(0.02)$ & $(0.04)$ \\
\hline Observations & 304 & 304 & 304 & 266 \\
\hline Instruments & \multicolumn{3}{|c|}{$\begin{array}{c}\text { antiq yrind legsoc legfr legbr } \\
\text { poplag polbiaslag Tropic Ldlock } \ln Y_{0}\end{array}$} & $\begin{array}{c}\text { antiq yrind } \\
\text { legsoc legfr legbr } \\
\text { poplag natres } \\
\text { Tropic Ldlock } \ln Y_{0} \\
\end{array}$ \\
\hline Sargan Test Stat. & 3.99 & 3.54 & 6.32 & 3.12 \\
\hline$P$-value & $(0.26)$ & $(0.32)$ & $(0.10)$ & $(0.37)$ \\
\hline Cragg-Donald & 1.29 & 1.29 & 1.29 & 2.00 \\
\hline
\end{tabular}

Notes: Standard errors in parentheses: ${ }^{a},{ }^{b}$ and ${ }^{c}$ denote coefficients significantly not null respectively at the $1 \%, 5 \%$ and $10 \%$ level.

In the ratio of model $3.1, i$ includes expense on economic activities, housing and defense. In the ratio of model 3.2, $i$ includes expense on economic activities, housing, defense and culture. In the ratio of model $3.3, g$ only includes expense on education. In model 3.4, the instrument natres is substituted for polbiaslag. 
Département des Sciences Économiques de l'Université catholique de Louvain

Institut de Recherches Économiques et Sociales

Place Montesquieu, 3

1348 Louvain-la-Neuve, Belgique 